\title{
ENFOQUE QUÍMICO DEL DETERIORO Y BIODETERIORO \\ DE ROCAS CALCÁREAS CONFORMANTES DE MONUMENTOS PATRIMONIALES DE IMPORTANCIA HISTÓRICA Y CULTURAL
}

\author{
ROY DAVID TATIS CASTRO ${ }^{1}$, AIDA LILIANA BARBOSA \\ LÓPEZ ${ }^{2}$
}

Recibido el 18 de agosto de 2012 y aprobado el 11 de diciembre de 2012

\section{RESUMEN}

Los monumentos pétreos declarados como patrimonio histórico son deteriorados a través del tiempo por efecto de agentes físicos, químicos y medioambientales. Estos últimos dependen en gran medida de la ubicación geográfica del inmueble, dichos agentes son: el régimen de vientos que desgasta la roca erosionándola; temporadas de lluvia que al contener sales disueltas causan corrosión por reacciones químicas de estas con la matriz del material calcáreo solubilizando el carbonato de calcio el cual es su principal componente; radiación solar durante todo el año causante de decoloramiento; humedad que permite el establecimiento de formas de vida. Las actividades antropogénicas que no son amigables con el ambiente son otro factor determinante, las emisiones de gases vehiculares por ejemplo, deterioran en gran medida los monumentos de piedra antiguos por ser agentes ácidos altamente corrosivos. Se crean así las condiciones para el establecimiento y proliferación de organismos vivos en la piedra tales como bacterias, algas, hongos, líquenes y plantas que por ser invasivos y colonizadores causan biodeterioro. Dado que los metabolismos de estas especies involucran el consumo de sustratos químicos orgánicos e inorgánicos presentes en la roca, son otro factor que va en detrimento de la estabilidad, durabilidad, y apariencia estética de la misma.

\section{PALABRAS CLAVE}

Deterioro, biodeterioro, monumentos históricos de piedra, corrosión pétrea, meteorización de piedra.

\section{CHEMICAL STANDPOINT ABOUT DETERIORATION AND BIODETERIORATION OF CALCAREOUS ROCKS THAT MAKE PART OF CULTURAL HERITAGE MONUMENTS}

\begin{abstract}
Stony monuments declared as cultural world heritage are deteriorated through the years because of physical, chemical and environmental agents which depend largely on their geographic location. Among these agents are: gust of, winds that wear away the stone eroding it; rainy seasons which bring dissolved salts and cause corrosion because of their chemical reaction with the calcareous material matrix which solubilizes
\end{abstract}


calcium carbonate which is their main component; because of solar radiation all through the year stones lose their color; high humidity allows plants and living forms to grow. Anthropogenic activities which are not environmentally friendly are other important factor: vehicle gas emissions, for example, deteriorate greatly old stone monuments because they are highly corrosive acids. This way, optimal conditions are created for fungi, algae, bacteria, lichens and plants which are invasive and colonizing to live on the stone surface and cause biodeterioration. Since metabolisms of these species involve consumption of inorganic substrates that are present in the stones, they become another factor affecting monument's durability, stability, and aesthetic appearance.

\section{KEY WORDS}

Deterioration, biodeterioration, cultural world heritage stony monuments, stone corrosion, stone weathering.

\section{INTRODUCCIÓN}

Las rocas son materiales que fueron estables a las presiones y temperaturas altas presentes en la corteza terrestre en el momento en que formaron. Sin embargo, una vez expuestas a la superficie y como consecuencia de su sometimiento a regímenes diferentes de presión y temperatura además de su interacción con sustancias como agua, gases atmosféricos y organismos vivos, sufrieron un proceso denominado meteorización. Al referirse a rocas conformantes de construcciones de importancia histórica y cultural, se concibe a la meteorización como su decaimiento o degradación bien sea por medios naturales o artificiales propios de hallarse expuestas a las condiciones ambientales de su ubicación geográfica (AlAlgha, 2006), haciendo inestables a las rocas que las conforman debido a las alteraciones en sus propiedades físicas como pérdidas de dureza, masa, superficie, forma y color además de alteraciones químicas evidenciadas a través de reacciones de los materiales que las conforman con agentes químicos del entorno (Mottershead et al., 2003). Los procesos de meteorización ocurren por acción y sinergia de muchos agentes y mecanismos entre los que se incluyen por mencionar algunos: radiación solar, vientos, humedad, contaminantes de naturaleza inorgánica cuya presencia es principalmente antropogénica (Zanardini et al., 2000), y contaminantes de naturaleza orgánica los cuales son liberados por acción metabólica de organismos que se asientan sobre ellas.

El deterioro se define como el cambio indeseable en las propiedades físicas y químicas de un material determinado. En el caso de las rocas de interés histórico, la ya mencionada meteorización es la principal causante de este problema y depende en gran medida de las características estructurales y superficiales de las mismas, tales como su dureza y porosidad. Así, la meteorización se evidencia principalmente de las 
siguientes formas: a través de la presencia en la matriz de las rocas de sales disueltas en agua (las cuales provienen principalmente de las lluvias y de la espuma marina), y la presencia de especies retenedoras de humedad en su superficie causando pérdida de material por formación de oquedades (Borgia et al., 2000), la posterior cristalización de estas sales disueltas ocasionan una pérdida de estabilidad (Colston, Watt \& Munro, 2001; Pope, Meierding \& Paradise, 2002; Herrera \& Videla, 2004), además de ser responsables de solubilizar el carbonato de calcio que las conforma; desgastes en el material cementante que las mantiene unidas por desprendimiento de juntas son ocasionados por la acción del régimen de vientos a través de un fenómeno conocido como erosión; la disminución considerable de la dureza del material pétreo que la humedad origina se traduce en una menor resistencia (Barbosa, Buendía \& Cortés, 2007), y por último las altas temperaturas también son causantes de la degradación mecánica de la piedra vía expansión hídrica-contracción térmica diferencial de los minerales (Papida, Murphy \& May, 2000).

Por otro lado, los contaminantes atmosféricos causan deterioro acelerado del material pétreo conformante de monumentos de interés histórico, debido a que interactúan químicamente con la matriz calcárea del mismo dañándolo seriamente y a veces, incluso, de forma irreversible debido a la corrosión que causan (Zanardini et al., 2000). Dichos contaminantes pueden ser de naturaleza orgánica, siendo los hidrocarburos poliaromáticos, formiatos, acetatos, y oxalatos los compuestos más comúnmente encontrados y que de forma considerable afectan las fachadas de los monumentos históricos (Saiz-Jiménez, 1991; Marioni et al., 2003). Los gases de naturaleza inorgánica como sales marinas, óxidos de azufre (SOx), óxidos de nitrógeno (NOx) y dióxido de carbono son también muy agresivos químicamente (Tittarelli, Moriconi \& Bonazza, 2008). Ambos tipos de contaminantes, tanto orgánicos como inorgánicos, se depositan por vía seca o húmeda (Charola \& Ware, 2002) tanto dentro como fuera de la superficie de las rocas conformantes de los monumentos históricos dañándolas capa por capa, lo que tiene por consecuencia inmediata un cambio en su color. Por tomar un ejemplo, la acción del dióxido de azufre sobre la superficie de las rocas causa en estas la aparición de costras negruzcas debido a la formación superficial de yeso (CaSO4) (el cual tiene un color grisáceo oscuro), además de la combinación de este con partículas contaminantes flotantes en el viento como el polvo, las esporas y el polen, por mencionar algunos (Slezakova et al., 2011).

Las actividades de naturaleza antropogénica derivadas del uso de aparatos eléctricos, combustibles fósiles para la generación de energía y transporte, e inclusive la quema de desechos, contribuye de manera considerable a incrementar la concentración de compuestos químicos corrosivos lo que causa una aceleración en los procesos de deposición sobre la superficie de las rocas calcáreas de monumentos de interés histórico. Todos los agentes que se han mencionado, propician las condiciones necesarias para que prosperen microorganismos y plantas superiores, dada la cantidad de 
especies químicas que nutren y mantienen vivos a esos organismos, pudiéndose decir hasta este punto que el biodeterioro que estos causan de una u otra manera es una consecuencia directa del deterioro que sufre el material pétreo de interés cultural (Zanardini et al., 2000).

Se entiende por biodeterioro a todo aquel cambio indeseable en las propiedades de un material por acción de la actividad vital de organismos vivos. Esta definición nos permite diferenciar claramente al biodeterioro de otros campos de estudio que son muy similares, como la corrosión y la erosión de materiales los cuales también son causantes de efectos indeseables en las propiedades del material pétreo pero son influenciados por agentes químicos, físicos y mecánicos. En principio, se consideraba al biodeterioro como un proceso de degradación que se daba como consecuencia directa de los efectos iniciales de deterioro por agentes de tipo inorgánico, sin embargo, evidencias experimentales demostraron que los procesos a través de los cuales las rocas empiezan a ser atacadas por organismos vivos ocurren desde poco después de que la piedra sufre los efectos de exposición al medio ambiente, esto es, a concentraciones relativamente bajas de contaminantes de tipo atmosférico (Warscheid \& Braams, 2000; Allsopp, Seal \& Gaylarde, 2004; Nuhoglu et al., 2006). El biodeterioro es entonces un fenómeno que merece considerable atención dado que los organismos involucrados en él, a saber, bacterias (tales como cianobacterias y actinomicetos), algas, hongos, arqueobacterias, líquenes, protozoarios como mixomicetos y plantas (Crispim, Gaylarde \& Gaylarde, 2004), usan la matriz de la piedra rica en sustratos de tipo orgánico e inorgánico como fuente directa de nutrientes (Nuhoglu et al., 2006) y además liberan metabolitos alcalinos, o bien basados en ácidos orgánicos e inorgánicos los cuales son altamente deterioradores (Mitchell \& Gu, 2010), esto explica la evidencia experimental hallada en la literatura que demuestra que el proceso de biodeterioro en los monumentos de piedra es de 100 a 10000 veces más rápido que el que se da por corrosión química dada por los contaminantes atmosféricos (Young, 1996).

La comprensión completa de los mecanismos de deterioro de las rocas calcáreas en construcciones, es vital en el manejo y conservación de los mismos. Los monumentos de piedra poseen un gran valor intrínseco por ser insignes representantes de periodos de relevancia histórica y por ser cuota turística de valor incalculable; el hecho de ser declarados como patrimonios históricos por la UNESCO hace que se deban aumentar los esfuerzos por conservar su integridad física y arquitectónica por parte de los gobiernos, fundaciones privadas y diversas disciplinas como se muestra en el siguiente esquema (Pope, Meierding \& Paradise, 2002): 


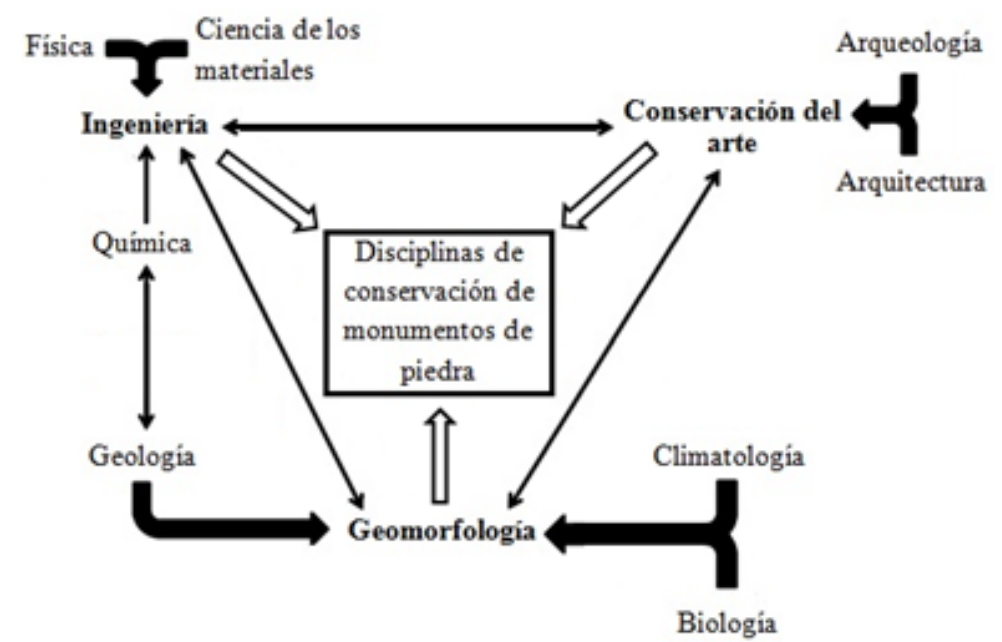

Figura 1. Relación interdisciplinaria en la conservación de monumentos históricos de importancia cultural.

El objetivo de este artículo de revisión es explicar los mecanismos químicos mediante los cuales se dan los procesos tanto de deterioro como de biodeterioro en rocas calcáreas conformantes de construcciones históricas, puesto que existe una carencia notoria en la literatura de establecer una relación directa y clara entre ambos procesos como coadyuvantes en el decaimiento y degradación (Herrera \& Videla, 2004).

\section{MECANISMOS DE METEORIZACIÓN POR AGENTES FÍSICOS Y MECÁNICOS DE ROCAS CALCÁREAS CONFORMANTES DE MONUMENTOS HISTÓRICOS DE IMPORTANCIA CULTURAL}

\section{Deterioro por acción del sol y la temperatura}

El sol produce un efecto marcado sobre el material pétreo de los monumentos de interés histórico. En días soleados se sobrecalienta por la radiación, dándose cambios dramáticos de temperatura cuando el sol se oculta debido a que en él se producen ciclos de expansión-contracción térmica que ocasionan daños irreversibles puesto que se producen reordenamientos en la estructura cristalina de las rocas haciéndolas menos resistentes.

Las variaciones en la temperatura tienen como consecuencia inmediata cambios en la saturación de vapor de agua denominados ciclos de humedad y secado dentro de los poros de la roca, lo que incrementa la concentración de las sales disueltas en ella llegando incluso a la precipitación cuando la solución se vuelve sobresaturada. Los ciclos de humedad y secado afectan el estado y la acción química del agua, la solubilidad de las sales, la rapidez de sus reacciones químicas y además se hallan ligados directamente con los ciclos de expansión y contracción térmica. Cuando los efectos de 
temperatura y humedad se combinan, el mecanismo que gobierna el deterioro del material pétreo se hace más complejo. El comportamiento generalmente heterogéneo de los minerales durante la ocurrencia de estos ciclos causa la desintegración de la roca calcárea (Ventikou et al., 2002).

La temperatura del aire es un factor determinante en el mecanismo mediante el cual se dan algunos metabolismos de ciertos organismos causantes de biodeterioro, estableciéndose estos en un rango de temperaturas de entre 20 y $35^{\circ} \mathrm{C}$ (Camuffo, 1998) incidiendo directamente sobre la velocidad de las reacciones implicadas en los mecanismos químicos de deterioro.

Hay un marcado desacuerdo acerca de considerar a la insolación como causal de deterioro y meteorización de la piedra conformante de monumentos históricos, tomándose más en cuenta otros mecanismos físico-químicos como los contaminantes ambientales, la humedad, las propiedades intrínsecas del material pétreo, entre otras; sin embargo, es bien sabido que los efectos de la variación de la temperatura sobre todo en países donde se dan las cuatro estaciones produce variaciones en el volumen de las construcciones históricas, dilatándose cuando se tienen temperaturas altas como en verano y contrayéndose cuando las temperaturas son más bien bajas como en invierno.

Por otro lado, la temperatura también afecta la emisión de contaminantes de naturaleza antropogénica ya que sus variaciones hacen fluctuar las necesidades humanas de comodidad y calidad de vida, lo que tiene como consecuencia directa un aumento en el uso de sistemas de calefacción o aire acondicionado que a su vez se traduce en un mayor consumo de fuentes de energía poco amigables con el medio ambiente (Watt et al., 2009).

\section{Deterioro por acción del viento}

Como ya se ha mencionado, el régimen de vientos interviene de forma importante en el proceso de meteorización del material pétreo, siendo más o menos variable dependiendo de la ubicación geográfica de los monumentos de piedra; su acción corrosiva se debe a que es capaz de arrastrar consigo agua, sales, polvo y gases influenciando así la deposición seca de contaminantes, la colonización biológica, y ciclos de humedad y secado (Watt et al., 2009). Si los monumentos en cuestión se hayan ubicados en zonas costeras, las partículas de arena son arrastradas a diversas velocidades colisionando con las zonas más bajas de las construcciones patrimoniales. Tales colisiones son capaces de remover físicamente materiales conformantes de estas, lo que se conoce como erosión. Cuando las partículas que el viento arrastra son químicamente activas, como por ejemplo iones cloruro, el proceso de meteorización se hace aun más agresivo. Por tanto, se puede decir que si hay monumentos construidos cerca del mar el proceso de deterioro que estos sufren será más dramático y acelerado que en 
aquellos que se hallen lejos de las costas. Por lo general, los primeros $50 \mathrm{~cm}$ de material pétreo desde la superficie del suelo suelen estar mayormente meteorizados cuando se los compara con otras zonas más altas de tales monumentos (Al-Algha, 2006; Barbosa, Buendía \& Cortés, 2007).

\section{Deterioro por acción del agua}

El agua juega un papel muy importante en el proceso de decaimiento de las rocas calcáreas conformantes de monumentos históricos afectándolas en todas sus fases, a saber: hielo o nieve cuando se halla en fase sólida; lluvia, humedad, aguas subterráneas o incluso olas marinas cuando se halla en fase líquida; y vapor cuando se encuentra en fase gaseosa, en este último caso el agua es capaz de hacer variar la humedad relativa del aire ocasionando incrementos en el contenido de humedad en la roca. Cuando actúa sinérgicamente con condiciones dadas de temperatura $u$ otros factores, puede causar deterioro o incluso destruir totalmente los monumentos construidos de rocas calcáreas (Watt et al., 2009). El agua es un agente de deterioro de naturaleza tanto física como química. En el primer caso, ingresa en la matriz de la roca en forma de vapor a través del fenómeno de la capilaridad provocando la presencia de humedad a través de un efecto conocido como higroscopicidad, esto es, agua ingresando en forma líquida se retendrá dentro de la matriz calcárea de la piedra (Zanardini et al., 2000) bien sea por acción de sales disueltas (Cataldo et al., 2005; Maurício et al., 2005; Liu Zhi et al., 2011) o por la presencia de organismos en forma de biofilms (Flores, Lorenzo \& Gómez-Alarcón, 1997). En el segundo caso, el agua actúa como solvente de gases derivados de actividades antropogénicas (Tittarelli, Moriconi \& Bonazza, 2008) además de sales, las cuales son principales responsables del proceso de corrosión del material pétreo, esto la convierte en la fuente principal de vida causante de biodeterioro. Sin embargo, debe aclararse que el tamaño de poros del material pétreo conformante de monumentos históricos es un factor clave que determina el hecho de si el flujo capilar del agua en su interior será significativo o no (Borgia et al., 2000; Papida, Murphy \& May, 2000), pudiéndose decir con ello que la estructura de la roca calcárea y sus poros permiten, entre otras propiedades, su meteorización ya que es precisamente por ellos que tal proceso tiene lugar, puesto que además de agua los poros acumulan también sus contaminantes disueltos. En gran medida, la cualidad de una piedra de ser resistente al intemperismo o no depende entonces de qué tan porosa sea. Así, la estructura de los poros permite obtener información acerca del grado de degradación con gran precisión. Una de las mayores amenazas que afrontan los materiales calcáreos de interés histórico, son los cambios cíclicos en sus contenidos de humedad, lo que produce sobrepresiones dadas por la cristalización/hidratación y recristalización de sales que pueden estar disueltas en el agua, ello quiere decir que es menos dañino el hecho de tener un alto pero estable contenido de humedad en vez de tenerlo bajo pero variable. De esta manera, se puede concluir que en ausencia de agua y sus contaminantes disueltos, las reacciones químicas 
entre estos y la matriz calcárea de las rocas serían prácticamente nulas debido a que los principales procesos de meteorización como los fenómenos de transporte en los que están involucradas las sales disueltas del agua (migración, cristalización y recristalización) no tomarían lugar. El agua genera también estrés mecánico (Pérez Bernal \& Bello López, 2000); la expansión hídrica ocurre cuando las rocas de interés histórico al tener una porosidad aumentada por efecto del intemperismo se saturan de agua por capilaridad, lo que hace que estas interactúen químicamente con sus componentes aumentando su volumen y disminuyendo su resistencia mecánica (Sebastián et al., 2008).

\section{MECANISMOS DE METEORIZACIÓN POR AGENTES QUÍMICOS DE ROCAS CALCÁREAS CONFORMANTES DE MONUMENTOS HISTÓRICOS DE IMPORTANCIA CULTURAL}

\section{Tipos de contaminantes atmosféricos}

En principio la atmósfera es una capa delgada de gas que se extiende por toda la tierra y se halla conformada principalmente de nitrógeno $(78 \%)$ y oxígeno $(21 \%)$ junto a otros gases como argón, neón, hidrógeno, helio, metano, criptón, xenón, ozono, entre otros. La definición de contaminación atmosférica suele ser muy relativa, sin embargo, cuando se hace referencia a construcciones históricas se la puede definir como cualquier condición en la cual las sustancias químicas presentes en la atmósfera poseen concentraciones mayores a las usuales de tal manera que causan un efecto apreciable en estos materiales (Jain \& Mishra, 1993). Las sustancias que causan este tipo de situaciones se conocen como contaminantes atmosféricos y pueden provenir de fuentes naturales o antropogénicas. Las primeras involucran erupciones de volcanes, rayos, procesos microbiológicos en el suelo (acción bacteriana), degradación de desechos orgánicos. Por otro lado, los contaminantes provenientes de fuentes antropogénicas, por ejemplo actividades como generación de energía, funciones domésticas y de transporte. Así, los contaminantes más representativos incluyen al dióxido de carbono, óxidos de azufre y nitrógeno, amoniaco, vapor de agua, ozono, hidrocarburos y metales pesados. La mayoría de los contaminantes provienen de ambos tipos de fuentes (Watt et al., 2009). Además, estos pueden ser primarios siempre que sean emitidos directamente a la atmósfera desde diferentes fuentes como son chimeneas industriales, emisiones domésticas y automotrices, etc. Mientras que los contaminantes secundarios se forman en la atmósfera por interacción y transformación química de los contaminantes primarios, como por ejemplo el dióxido de azufre se convierte en trióxido de azufre el cual a su vez se combina con humedad ambiental para formar ácido sulfúrico (Naresh, Sundar \& Shukla, 2006; Watt et al., 2009).

\section{Deposición húmeda y seca de contaminantes químicos}


Como ya se ha dicho, el sol, el agua y el viento físicamente causan deterioro en el material pétreo conformante de monumentos históricos de importancia cultural, pero además sirven de medio para que los contaminantes químicos deterioren las rocas calcáreas de construcciones históricas de importancia cultural a través de procesos de deposición seca y húmeda como se muestra en la figura siguiente:

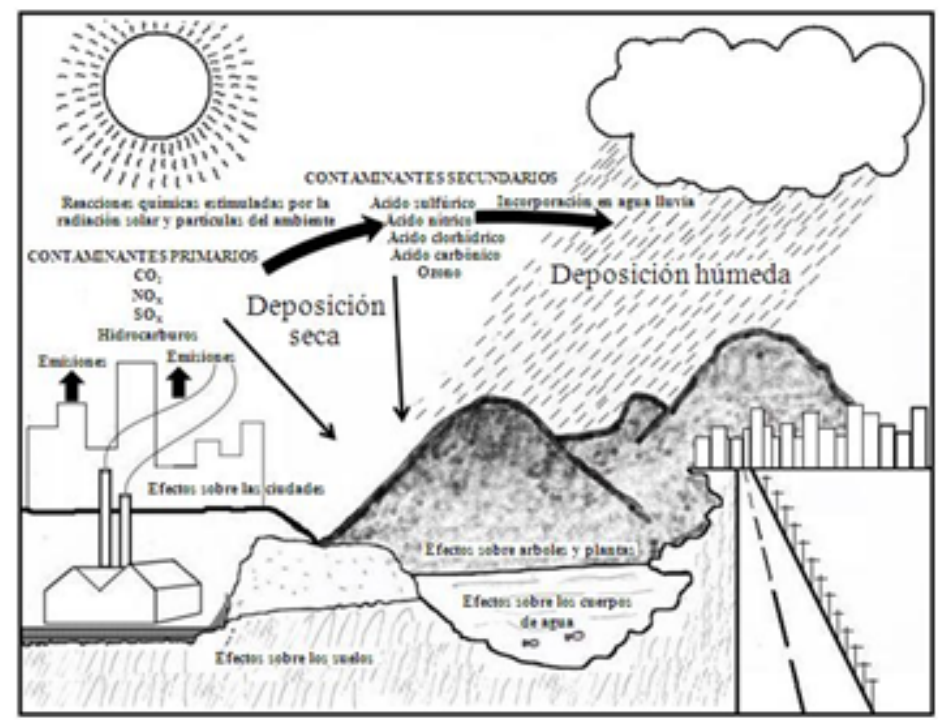

Figura 2. Vías principales de deposición de contaminantes.

La deposición seca de contaminantes químicos sobre superficies de roca calcárea de interés histórico, suele darse en sitios donde la contaminación ambiental es alta, dándose como resultado de la transferencia de gases contaminantes y/o partículas incluyendo aerosoles de la atmósfera al monumento por acción del viento, esto es, sin ayuda de hidrometeoros (Marimoni et al., 2003). En general, la deposición seca de contaminantes se da por medio de fuentes cercanas, lo que se conoce como deposición a rango corto, viéndose incrementada por la composición química y concentración de los contaminantes, la magnitud en la turbulencia del viento, uniformidad y humedad en la superficie receptora de la roca y la afinidad que esta tiene por dichos contaminantes. Cuando los contaminantes que se depositan son de naturaleza gaseosa, su deposición seca se da a través de difusión molecular, mientras que si nos referimos a material particulado de dimensiones menores a un micrón entonces el mecanismo de deposición se da por difusión browniana o turbulenta (Pesava et al., 1999). Uno de los efectos de la contaminación de este tipo de contaminantes, es la formación de una costra negruzca sobre la superficie de las construcciones. Cuando estas capas absorben la radiación proveniente del sol reducen la cantidad de luz que la superficie por naturaleza debe reflejar, este efecto se conoce como "ensuciamento". Las partículas más pequeñas suelen adherirse por medio de fuerzas de tipo Van der Waals incluso en superficies verticales. Generalmente aquellas que poseen más de 20 micrones se depositan por sedimentación gravitacional. Cabe anotar que el proceso de deposición 
depende mucho de las características de la superficie así como de la presencia de cargas en los contaminantes. La concentración de los contaminantes encontrada dentro de unos pocos centímetros sobre la superficie receptora junto con las condiciones microclimáticas son los más relevantes factores a tener en cuenta en el proceso de deposición química, tales condiciones pueden ser totalmente diferentes de aquellas que hay en la atmósfera circundante, esto es, a una distancia de unos cuantos metros de la superficie implicada en la deposición.

Por otro lado, la deposición húmeda generalmente juega un papel menos relevante que la deposición seca de contaminantes sobre las rocas calcáreas de interés histórico. Sin embargo, en lugares en los que la contaminación ambiental no es tan alta como es en zonas rurales, puede ser un proceso tan importante como la deposición seca. La deposición húmeda de contaminantes ambientales se da por efecto de la incorporación de sustancias contaminantes disueltas en solución acuosa por ejemplo a través de gotas de rocío y más evidentemente a través del agua proveniente de las lluvias (Marimoni et al., 2003). En contraste a lo que ocurre en la deposición seca, los contaminantes que se incorporan a las gotas usualmente se producen en fuentes distantes en comparación con el proceso seco que, como se dijo, se da por deposición a rango corto, además la deposición húmeda afecta solamente a la superficie de la construcción histórica mientras que la deposición seca la afecta en toda su extensión (Charola \& Ware, 2002). La deposición química tanto seca como húmeda de los contaminantes que intervienen en el mecanismo químico del deterioro y corrosión de las piedras conformantes de monumentos de interés histórico, se explicará ahora.

\section{Deterioro por acción de sales}

Ampliamente se ha aceptado que la presencia de sales solubles (las cuales pueden provenir tanto de fuentes geogénicas a saber: la piedra misma, aguas residuales del suelo, rocío marino, o interacciones dadas por incompatibilidades en casos en que los materiales de las construcciones históricas sean de naturalezas distintas, como de fuentes antropogénicas: polución ambiental, desechos orgánicos, etc.), producen deterioro afectando materiales como metales, cerámicas, ladrillos, concreto y rocas calcáreas conformantes de monumentos de interés histórico por sus efectos de cristalización y por sus reacciones químicas con los componentes intrínsecos del material pétreo (Colston, Watt \& Munro, 2001; Alves, Sequeira Braga \& Trancoso, 2002; Doehne, 2002; Pope, Meierding \& Paradise, 2002; Rijniers et al., 2003; Al-Algha, 2006; Andriani \& Walsh, 2007; Benavente et al., 2007; Cardell, Benavente \& Rodríguez-Gordillo, 2008; Espinosa-Marzal \& Scherer, 2010; Liu Zhi et al., 2011) llegándose a considerar como las mayores causantes de meteorización del material calcáreo de las construcciones de interés cultural (Zedef et al., 2007). Las sales más relevantes en el proceso de deterioro son las que poseen iones de tipo sulfato, nitrato, potasio, sodio, magnesio y cloruro (Maurício et al., 2005), este último es considerado el mayor 
causante de decaimiento cuando el monumento se halla en proximidades costeras (Harris, 2001; Al-Algha, 2006). Investigaciones sustanciales de este fenómeno que incluyan la anisotropía y heterogeneidad de las rocas todavía son muy escuetas (Ruedrich et al., 2007). Sin embargo, se ha podido comprobar que el deterioro en este material ocurre como consecuencia del fenómeno de cristalización que se da tanto en la superficie expuesta de la roca como en su interior donde genera sobrepresiones dependiendo del tipo y tamaño de los poros de las rocas, su grado de saturación y la diferencia de energía que hay entre el cristal y la pared del poro. Este último concepto está relacionado con el hecho de que la presión de cristalización es menor en poros más grandes y mayor en poros más pequeños (Flatt, 2002; Cardell et al., 2003; Benavente et al., 2004). Cuando las sales solubles son móviles en suficiente agua (o vapor de agua) penetran en los poros por capilaridad y cualquier decrecimiento subsecuente de la humedad relativa o de la temperatura hará que migren y se sobresaturen en la medida en que el agua se evapora. Así, por cristalización se entiende al proceso mediante el cual el agua que ha disuelto a tales sales se evapora depositándolas en estado sólido (Espinosa, Franke \& Deckelmann, 2008). Otro fenómeno análogo a la cristalización de las sales se basa en el hecho de que estas son susceptibles de hidratarse, por tanto pueden hallarse en más de un estado de hidratación, y en la conversión de un estado a otro hay un incremento en el volumen que la sal en cuestión ocupa. Esto provoca daños por sobrepresión y estrés mecánico dentro de los poros de las rocas. El ejemplo más evidente de este fenómeno es el sulfato de sodio, el cual es una de las sales que causan más deterioro por su capacidad de existir en forma anhidra thenardita $\left(\mathrm{Na}_{2} \mathrm{SO}_{4}\right)$ o en su forma decahidratada mirabilita $\left(\mathrm{Na}_{2} \mathrm{SO}_{4} \cdot 10 \mathrm{H}_{2} \mathrm{O}\right)$; cuando la thenardita se convierte en mirabilita incrementa su volumen más de tres veces, sin embargo hay que tener en cuenta que estas conversiones no se dan espontáneamente sin haber primero una disolución y luego una recristalización a la nueva forma hidratada (Doehne \& Price, 2010). En síntesis, puede decirse que en el proceso de deterioro que las sales causan se producen ciclos

de disolución/migración/cristalización/disolución/hidratación/recrista lización que conllevan a un aumento en la concentración de las mismas en la superficie y dentro de la roca precipitándose. Se debe aclarar que el proceso de hidratación depende de la sal causante del deterioro. En algún punto su concentración es suficiente de tal manera que la cristalización ocurre dentro de los poros, proceso denominado criptoflorescencia (o subflorescencia) que se define como el efecto que sobre las paredes de los poros tienen las sales que han quedado cristalizadas en ellos, ejerciendo presión suficiente como para causar deterioro severo que se traduce en un aumento en el tamaño de los mismos como se muestra en la siguiente figura: 


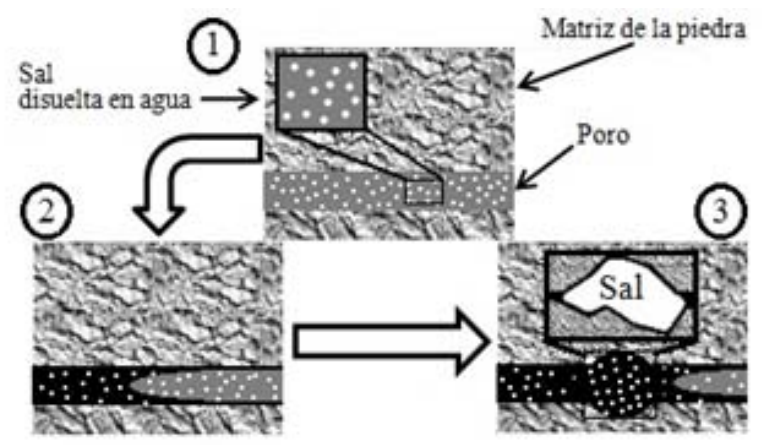

Figura 3. Proceso de cristalización de sales dentro de los poros de una roca de interés histórico (criptoflorescencia). (1) La sal disuelta en agua entra en el sistema de poros por capilaridad. (2) A medida que el agua se evapora como producto de variaciones en la temperatura y la humedad, hay una migración de las sales y una sobresaturación con lo que su concentración se ve aumentada. (3) Una vez la sal cristaliza ejerce presión dentro de los poros lo que causa ensanchamiento y agrietamiento de la matriz en su interior.

La criptoflorescencia es causante de grietas, desmoronamiento y pulverización de la construcción histórica (Al-Algha, 2006; Andriani \& Walsh, 2007). Cuando dicha evaporación se da en el exterior de la superficie del material pétreo afectado, entonces las sales cristalizadas forman una inofensiva (debido a que no afecta en nada la resistencia del material pétreo) pero poco estética deposición en la superficie llamada eflorescencia (Colston, Watt \& Munro, 2001; Espinosa, Franke \& Deckelmann, 2008; Espinosa-Marzal \& Scherer, 2010). Si se comparan sus efectos, la criptoflorescencia es mucho más dañina (Benavente et al., 2007; Espinosa, Franke \& Deckelmann, 2008) y el hecho de que se dé la una sobre la otra depende de (1) el tipo de sal o mezcla de sales disueltas por sus reactividades (Andriani \& Walsh, 2007), (2) humedad y temperatura por influir en la velocidad de evaporación haciendo variar el microclima de la superficie afectada, (3) la estructura de los poros del material, teniéndose evidencia de que los poros más grandes de aproximadamente 1-10 $\mu \mathrm{m}$ son afectados primero por la criptoflorescencia y una vez estos se hallan saturados el proceso sigue con los poros de menor tamaño de 0,01 a 0,1 $\mu \mathrm{m}$ (Andriani \& Walsh, 2007; Benavente et al., 2007; Espinosa, Franke \& Deckelmann, 2008), (4) la tensión superficial y viscosidad de la solución salina (Ruiz-Agudo et al., 2007).

La cinética también puede predecir la ocurrencia de un fenómeno sobre otro. Si asignamos a la velocidad de evaporación de agua de la superficie de la roca el valor $k 1$ contra la velocidad de rehidratación $k 2$. El valor de $k 1$ estará dado en función de la temperatura, humedad del aire y corrientes de aire locales, mientras que $k 2$ depende de las propiedades físicas de la piedra como radio de poros, viscosidad y longitud del camino que hay desde la fuente de la solución salina al sitio de la evaporación.

Si $k 2 \geq k 1$, ocurrirá eflorescencia puesto que la rehidratación asegura que solo habrá evaporación en la superficie por lo que las sales cristalizarán solo en esta zona. $\mathrm{Si}$, por otro lado $\mathrm{k} 2<$ 
$k 1$, la velocidad de migración de la solución a través del sistema de poros del material es tan baja como para permitirle a la superficie mantener un estado hidratado, en este caso habrá criptoflorescencia ya que las zonas secas se desarrollan justo debajo de la superficie y el soluto se deposita dentro de la roca en la frontera entre regiones húmedas y secas (Colston, Watt \& Munro, 2001).

La fuente más común y evidente de sales es el mar, a tal punto que cuando el monumento se halla cerca o incluso parcialmente sumergido en él, su deterioro es todavía mayor (Maurício et al., 2005; Al-Algha, 2006; Andriani \& Walsh, 2007). Las especies iónicas son arrastradas por acción del régimen de vientos marinos llegando al monumento en forma de spray formando la denominada niebla salina (Coussy, 2006). Se tomarán en consideración a los iones cloruro y bicarbonato en esta revisión por hallarse en mayor proporción en el agua de mar en forma de cloruro de sodio $(\mathrm{NaCl})$, y al bicarbonato como producto dado de la reacción que se produce entre el primero y el carbonato de calcio $\left(\mathrm{CaCO}_{3}\right)$ conformante de la roca. El mecanismo químico de deterioro por cloruro y en general por otro tipo de sales involucra dos pasos, el primero implica la disolución en agua de la sal soluble formando especies ácidas que son corrosivas incluso a concentraciones bajas, y el segundo paso implica el ataque de dichos ácidos a la matriz de la piedra del monumento histórico. El siguiente mecanismo ilustra de mejor manera este proceso:

$$
\begin{gathered}
2 \mathrm{Cl}^{-}+\mathrm{H}_{2} \mathrm{O} \rightarrow 2 \mathrm{HCl}_{(a \mathrm{Cc})}+\mathrm{O}(1) \\
\mathrm{CaCO}_{3}+\mathrm{Cl}^{-}+\mathrm{H}^{+} \rightarrow \mathrm{CaCl}_{2}+\mathrm{HCO}_{3}^{-}(\mathbf{2}) \\
\text { Mecanismo } 1
\end{gathered}
$$

El cloruro puede presentarse de dos maneras, libre o enlazado, ambos actúan de formas distintas, bien sea por fijación, por absorción o por reacciones químicas, ambas formas alcanzan concentraciones en la atmósfera entre 0,5 y $5 \mu \mathrm{g} / \mathrm{m}^{3}$. Los cloruros libres se hallan disueltos y como su nombre lo indica sufren efectos de cristalización/migración/recristalización que se han explicado; los cloruros enlazados son aquellos que se hallan formando sales tanto cálcicas como sódicas luego del proceso de evaporación del agua que las contuvo (Silva \& Simão, 2009).

\section{Corrosión de rocas calcáreas por acción de gases (SOx)}

El deterioro de piedras calcáreas dado por degradación química, se considera como causado en buena parte por efecto de los contaminantes atmosféricos tanto primarios como secundarios y sus efectos inmediatos como por ejemplo la deposición seca y húmeda de gases ácidos y aerosoles, sin dejar nunca de lado la dependencia que el deterioro tiene sobre las propiedades intrínsecas de la roca (Grossi \& Murray, 1999). Este deterioro en monumentos de importancia cultural se ve dramáticamente acelerado por la acción de contaminantes presentes en la atmósfera como los gases de azufre SOx. Los efectos dañinos que estos causan se conocen desde hace más 
de un siglo y ha habido un incremento en el interés por investigar el mecanismo de corrosión relacionado con ellos ya que tienen en gran proporción una naturaleza antropogénica como actividades industriales, combustiones producto de la quema de carbón y otros combustibles fósiles como emisiones de motores de combustión diesel (Bede, 2000). El dióxido de azufre $\mathrm{SO}_{2}$ es quizá el gas $\mathrm{SOx}$ más representativo por su poder corrosivo. Este puede emitirse también de fuentes naturales las cuales superan con gran diferencia las cantidades dadas antropogénicamente como erupciones volcánicas (la cual contribuye en más del $20 \%$ de las emisiones anuales de este contaminante) (Watt et al., 2009), niebla salina arrastrada desde el mar, y lluvias ácidas, por mencionar algunos (Slezakova et al., 2011). Hoy en día se sabe que el dióxido de azufre y los óxidos de nitrógeno son componentes gaseosos que reaccionan directamente con la superficie del material pétreo de monumentos históricos formando ácidos en presencia de agua y agentes oxidantes. Estos ácidos junto con el carbonato de calcio forman sales responsables de subflorescencias y eflorescencias en las rocas deteriorándolas de forma considerable (Massey, 1999). El dióxido de azufre por su parte es quizá el contaminante más agresivo de piedras de interés histórico (Charola \& Ware, 2002) debido a que forma yeso $\left(\mathrm{CaSO}_{4} \cdot 2 \mathrm{H}_{2} \mathrm{O}\right)$ a modo de costras en su superficie y este al ser unas cien veces más soluble $(0,21 \mathrm{~g} / 100 \mathrm{cc})$ que su principal conformante el carbonato de calcio $\left(\mathrm{CaCO}_{3}\right)(0,0014 \mathrm{~g} / \mathrm{cc})$ (Harris, 2001) puede ser fácilmente solubilizado por el agua de las lluvias provocando pérdida de material (Sánchez Sanjurjo, Vidal Romaní \& Alves, 2011).

La formación de yeso implica un aumento en el volumen del material en comparación con el carbonato de calcio, su formación genera concentración de estrés mecánico dentro de la estructura de la roca causando separación y pérdida de cohesión entre fragmentos de considerable tamaño de la roca. Esta pérdida suele darse en un rango comprendido entre 30 y $50 \%$, ocurriendo en gran proporción cuando las costras meteorizadas alcanzan cierto espesor y caen de la roca ya que las superficies involucradas presentan alta porosidad y disgregación en comparación con la original (Bello \& Pérez Bernal, 2003). Es también responsable del fenómeno de expansión térmica diferencial en el sentido de que las zonas con mayor presencia de costras negras son más susceptibles a absorber mayor cantidad de radiación solar. Por último, la formación de yeso por acción de contaminantes de tipo SOx induce la retención de agua por su cualidad de ser higroscópico.

La deposición de dióxido de azufre puede darse por vía seca o húmeda, la primera implica la adsorción sobre la piedra de este contaminante en su fase gaseosa, este proceso depende de factores ambientales y características de la superficie receptora como la concentración de $\mathrm{SO}_{2}$, temperatura, contenido de humedad, turbulencia del régimen de vientos, presencia de catalizadores ambientales o superficiales y la morfología de la piedra como porosidad, área superficial y uniformidad (Bede, 2000). Por otro lado, la deposición del dióxido de azufre por vía 
húmeda implica la disolución de este gas en agua lluvia lo que se conoce como "lluvia ácida", una vez que se deposita por esta vía sobre el material pétreo del monumento entonces interacciona químicamente con él corroyéndolo (Striegel et al., 2003).

El mecanismo químico que describe el proceso de corrosión por acción del dióxido de azufre se denomina sulfatación, si hay formación previa de sulfito de calcio (deposición seca), la formación de yeso se da por reacción entre el carbonato de calcio con este contaminante como se muestra en el siguiente mecanismo (Böke et al., 1999):

$$
\begin{aligned}
& \mathrm{H}_{2} \mathrm{O}+\mathrm{SO}_{2(g)} \leftrightarrows \mathrm{SO}_{2} \cdot \mathrm{H}_{2} \mathrm{O}_{(\mathrm{acl})} \leftrightarrows \mathrm{H}^{+}+\mathrm{HSO}_{3}^{-}(3) \\
& \mathrm{HSO}_{3}^{-} \leftrightarrows \mathrm{H}^{+}+\mathrm{SO}_{3}^{2-}(4) \\
& \mathrm{CaCO}_{3(s)}+\mathrm{H}^{+} \rightarrow \mathrm{Ca}^{2+}+\mathrm{HCO}_{3}^{-}(\mathbf{5}) \\
& \mathrm{HCO}_{3}^{-}+\mathrm{HSO}_{3}^{-} \rightarrow \mathrm{SO}_{3}^{2-}+\mathrm{H}_{2} \mathrm{CO}_{3}(6) \\
& \mathrm{SO}_{3}^{2-}+\mathrm{Ca}^{2+}+0,5 \mathrm{H}_{2} \mathrm{O} \leftrightarrows \mathrm{CaSO}_{3} \cdot 0,5 \mathrm{H}_{2} \mathrm{O}(7) \\
& \mathrm{CaSO}_{3} \cdot 0,5 \mathrm{H}_{2} \mathrm{O}+\mathrm{H}^{+} \rightarrow \mathrm{Ca}^{2+}+\mathrm{HSO}_{3}^{-}(8) \\
& \mathrm{HSO}_{3}^{-}+\mathrm{O}_{3} \rightarrow \mathrm{H}^{+}+\mathrm{SO}_{4}^{2-}+\mathrm{O}_{2}(9) \\
& \mathrm{HSO}_{3}^{-}+0,5 \mathrm{O}_{2} \rightarrow \mathrm{SO}_{4}^{2-}+\mathrm{H}^{+}(10) \\
& \mathrm{SO}_{4}^{2-}+\mathrm{Ca}^{2+}+2 \mathrm{H}_{2} \mathrm{O} \leftrightarrows \mathrm{CaSO}_{4} \cdot 2 \mathrm{H}_{2} \mathrm{O} \text { (11) }
\end{aligned}
$$

Inicialmente el $\mathrm{SO}_{2}$ que se haya adsorbido en la superficie del monumento, se disuelve en el agua presente en la humedad del ambiente formando posteriormente un ión hidrogenosulfito (reacción 3), este último tiene carácter ácido y se disocia para formar la especie sulfito (reacción 4) la cual se forma también por reacción entre los aniones bicarbonato dados de la descomposición catalizada por ácidos del carbonato de calcio (reacción 5) e hidrogenosulfito (reacción 6). El sulfito reacciona posteriormente con los iones calcio formando sulfito de calcio hemihidratado (reacción 7) el cual se disocia en medio ácido para dar nuevamente iones hidrogenosulfito (reacción 8) que eventualmente pueden oxidarse bien sea por acción del oxígeno del ambiente o del ozono troposférico a iones sulfato (reacciones 9 y 10) los cuales son principales responsables de la formación de sulfato de calcio dihidratado (yeso) por su reacción con los iones calcio (reacción 11).

La otra posibilidad es la absorción de dióxido de azufre en la lluvia ácida (deposición húmeda), aerosoles líquidos de la atmósfera o capas húmedas soportadas en la superficie de monumento donde es oxidado para formar ácido sulfúrico que disuelve el carbonato de calcio para formar yeso según el mecanismo siguiente:

$$
\begin{gathered}
2 \mathrm{SO}_{2}+\mathrm{O}_{2} \rightarrow 2 \mathrm{SO}_{3}(12) \\
\mathrm{SO}_{3}+\mathrm{H}_{2} \mathrm{O} \rightarrow \mathrm{H}_{2} \mathrm{SO}_{4(a c)}(13) \\
\mathrm{H}_{2} \mathrm{SO}_{4(a c)} \leftrightarrows 2 \mathrm{H}_{(a c)}^{+}+\mathrm{SO}_{4(a c)}^{2-(14)} \\
\mathrm{CaCO}_{3}+\mathrm{H}^{+} \longrightarrow \mathrm{Ca}^{2+}+\mathrm{HCO}_{3}^{-}(15) \\
\mathrm{Ca}^{2+}+\mathrm{SO}_{4}^{2-}+2 \mathrm{H}_{2} \mathrm{O} \rightarrow \mathrm{CaSO}_{4} \cdot 2 \mathrm{H}_{2} \mathrm{O}(16) \\
\text { Mecanismo } 3
\end{gathered}
$$


En el primer paso el $\mathrm{SO}_{2}$ se oxida a trióxido de azufre $\mathrm{SO}_{3}$ (reacción 12), cabe destacar que esta reacción se ve fuertemente afectada por la presencia en la atmósfera de oxígeno y por varios catalizadores arrastrados por contaminantes sólidos como materia carbonácea, polvos finos, etc. (Giavarini et al., 2008). Posteriormente el $\mathrm{SO}_{3}$ reacciona con agua para dar ácido sulfúrico (reacción 13) que disuelto en agua aporta iones hidrógeno (reacción 14) los cuales disocian al carbonato de calcio conformante de la roca (reacción 15), los iones calcio así derivados reaccionan entonces con iones sulfato formando yeso (reacción 16).

Es interesante anotar que esta última reacción en la que se forma yeso por deposición húmeda sobre la superficie de la roca por el dióxido de azufre, por lo general se detiene en un punto en el que la formación de $\mathrm{CaSO}_{4}$ forma una barrera protectora, sin embargo si hay presencia de cloruro de sodio $(\mathrm{NaCl})$ se dará un efecto sinérgico en el sentido de que el cloruro de sodio por su naturaleza higroscópica es un retenedor de humedad y acelera la deposición húmeda del dióxido de azufre (Harris, 2001), formando más ácido sulfúrico disponible para reaccionar con el carbonato de calcio a través del ya ilustrado mecanismo de sulfatación sobre la superficie del material pétreo como se ilustró en las reacciones (1) y (2), impidiendo así la formación de la mencionada capa protectora de yeso y contribuyendo a acelerar su corrosión. Por si fuera poco, el $\mathrm{NaCl}$ contribuye a que el yeso se solubilice más rápidamente (Lubelli, Van Hees \& Groot, 2004).

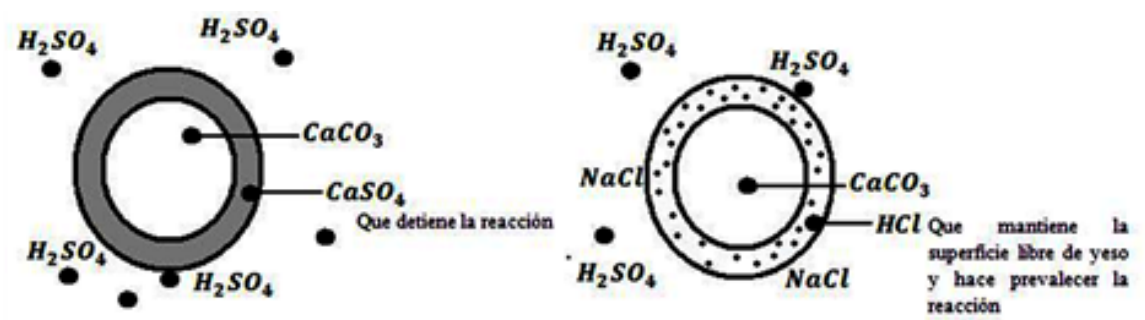

Figura 4. Acción del ion cloruro sobre la formación de yeso $\left(\mathrm{CaSO}_{4} \cdot 2 \mathrm{H}_{2} \mathrm{O}\right)$ en la superficie calcárea del material pétreo.

Los principales tipos de degradación en la superficie calcárea de los monumentos de piedra han sido referidos en la literatura en términos de áreas grises, blancas y negras. Las áreas blancas pueden encontrarse en superficies de monumentos expuestas a la influencia de las aguas de lluvia, lo cual causa un desprendimiento de material depositado como las sales, y por lo tanto la erosión del material pétreo. Las áreas grises por su parte, están principalmente compuestas de yeso, son zonas típicamente secas; con una alteración prácticamente nula de la morfología de la roca. Estas áreas representan el paso inicial del ataque superficial, donde las partículas de los contaminantes implicados, en este caso gases SOx, no interaccionan por el tiempo suficiente para que la reacción química con los componentes químicos de la superficie del material pétreo sea completa. Las áreas negras, denominadas también "costras negras", son incrustaciones heterogéneas y compactas presentes en superficies, las cuales no se hallan en 
contacto directo con el agua de las lluvias. En estas áreas, hay una acumulación de las partículas de gases contaminantes presentes en la atmosfera. La costra negra está compuesta principalmente de yeso, y se identifica por formar cristales en forma de aguja que crecen en forma perpendicular a la superficie de la roca (Giavarini et al., 2008). El color negro de la costra depende en gran medida de la deposición seca de partículas carbonáceas que provienen de derivados del petróleo, minerales silíceos los cuales son componentes característicos del polvo del suelo, niebla marina, y compuestos de metales pesados entre los que destacan $\mathrm{Fe}, \mathrm{Ti}, \mathrm{Pb}, \mathrm{Mn}, \mathrm{Cu}$, $\mathrm{Cr}, \mathrm{Zr}$ y Ni , estos compuestos se considera que alteran de una o de otra manera la formación de yeso sobre la superficie de la roca pero el mecanismo de estos procesos todavía no es claro (Böke et al., 1999).

\section{Corrosión de rocas calcáreas por acción de gases de tipo NOx}

Los gases de tipo NOx, los cuales son muy variados en la naturaleza y entre los que se encuentran: trióxido de nitrógeno $\left(\mathrm{NO}_{3}\right)$, pentóxido de dinitrógeno $\left(\mathrm{N}_{2} \mathrm{O}_{5}\right)$, óxido nitroso $\left(\mathrm{N}_{2} \mathrm{O}\right)$, oxido nítrico (NO) y dióxido de nitrógeno $\left(\mathrm{NO}_{2}\right)$ estos dos últimos siendo quizá los más importantes (Watt et al., 2009), pueden provenir de fuentes naturales como actividades biológicas del suelo dadas de las bacterias, erupciones volcánicas o tormentas eléctricas, por mencionar algunos, además se producen también de fuentes antropogénicas como el parque automotor y actividades de generación de energía en las que se involucren combustibles fósiles (Charola \& Ware, 2002). Su concentración en la atmosfera depende de la demanda en el ambiente de ozono $\left(\mathrm{O}_{3}\right)$ el cual actúa en el mecanismo de reacción como un importante agente oxidante (Massey, 1999). Así, los NOx pueden ser oxidados para dar los ácidos nítrico y nitroso que son sustancias causantes de decaimiento en las rocas calcáreas y en general en la naturaleza, por depositarse y causar corrosión a través de vía seca y húmeda por su carácter altamente ácido (Minotas Ruiz, 2002; Camaiti et al., 2007). El gas que más se libera a la atmósfera es el óxido nítrico (NO) que por ser un compuesto muy inestable suele oxidarse fácilmente a dióxido de nitrógeno $\left(\mathrm{NO}_{2}\right)$, el cual es un precursor del ácido nítrico. Las reacciones que estos involucran se muestran en el siguiente mecanismo denominado nitración:

$$
\begin{aligned}
& 2 \mathrm{NO}_{(g)}+\mathrm{O}_{2(g)} \rightarrow 2 \mathrm{NO}_{2(g)}(17) \\
& \mathrm{CaCO}_{3(s)}+3 \mathrm{NO}_{2(g)} \rightarrow \mathrm{Ca}\left(\mathrm{NO}_{3}\right)_{2(a c)}+\mathrm{NO}_{(g)}+\mathrm{CO}_{2(g)} \\
& 2 \mathrm{NO}_{2(g)}+\mathrm{H}_{2} \mathrm{O}_{(l)} \rightarrow \mathrm{HNO}_{3(\mathrm{ac})}+\mathrm{HNO}_{2(a c)}(19) \\
& 2 \mathrm{NO}_{2(g)}+\mathrm{O}_{3(g)} \rightarrow \mathrm{NO}_{3(g)}+\mathrm{O}_{2(g)}(2 \mathrm{O}) \\
& \mathrm{NO}_{2(g)}+\mathrm{NO}_{3(g)} \leftrightarrows \mathrm{N}_{2} \mathrm{O}_{5(g)}(21) \\
& \mathrm{N}_{2} \mathrm{O}_{5(g)}+\mathrm{H}_{2} \mathrm{O}_{(l)} \rightarrow 2 \mathrm{HNO}_{3(\mathrm{ac})}(22) \\
& \mathrm{HNO}_{3(a \mathrm{c})}+\mathrm{CaCO}_{3(s)} \rightarrow \mathrm{Ca}\left(\mathrm{NO}_{3}\right)_{2(\mathrm{ac})}+\mathrm{H}_{2} \mathrm{O}+\mathrm{CO}_{2(g)} \\
& \mathrm{CaCO}_{3(s)}+2 \mathrm{NO}_{2(g)}+1 / 2 \mathrm{O}_{2(g)} \rightarrow \mathrm{Ca}\left(\mathrm{NO}_{3}\right)_{2}+\mathrm{CO}_{2(g)} \\
& \text { Mecanismo } 4
\end{aligned}
$$


En el mecanismo químico de la nitración los gases NOx interaccionan con agentes oxidantes como ozono y agua para dar los ácidos nítrico y nitroso que posteriormente reaccionan con el carbonato de calcio $\left(\mathrm{CaCO}_{3}\right)$ conformante del material calcáreo convirtiéndolo en nitrato $\left[\mathrm{Ca}\left(\mathrm{NO}_{3}\right)_{2}\right]$ y nitrito $\left[\mathrm{Ca}\left(\mathrm{NO}_{2}\right)_{2}\right]$ de calcio, los cuales son sales muy higroscópicas (Kirkitsos \& Sikiotis, 1996). No obstante que son menos solubles que el cloruro de calcio y el yeso que se acaban de describir, no son menos dañinas para el material calcáreo puesto que su posterior solubilización en agua lluvia produce pérdidas irreversibles de material. Los gases de tipo NOx en especial el $\mathrm{NO}_{2}$ junto con el ozono, han mostrado ser agentes oxidantes importantes en el mecanismo de sulfatación del material pétreo de monumentos de importancia cultural catalizando reacciones de formación de ión sulfato (reacciones 10 y 12) actuando como catalizadores y mejorando la afinidad de la roca por este contaminante (Grossi \& Murray, 1999). Se ha demostrado que el NO2 es capaz de provocar una adsorción más fuerte de dióxido de azufre sobre el material calcáreo (Bai, Thompson \& Martínez-Ramírez, 2006).

\section{Acción oxidante del ozono en el deterioro químico de} monumentos históricos de roca calcárea

Como se mostró en la Figura 2, el ozono es un contaminante secundario debido a que no es emitido directamente a la atmósfera por acción natural ni por acción antropogénica, sino que se produce por la interacción de otros contaminantes como los NOx los cuales se hallan presentes en el ambiente y cuyas reacciones son catalizadas por los rayos UV solares (Watt et al., 2009).

$$
\begin{gathered}
\mathrm{NO}_{2}+\mathrm{UV} \rightarrow \mathrm{NO}+\mathrm{O}(25) \\
\mathrm{O}+\mathrm{O}_{2} \rightarrow \mathrm{O}_{3}(26) \\
\mathrm{NO}+\mathrm{O}_{3} \longrightarrow \mathrm{NO}_{2}+\mathrm{O}_{2}(27) \\
\text { Mecanismo } 5
\end{gathered}
$$

La ruptura fotolítica del $\mathrm{NO}_{2}$ (reacción 25) libera radicales oxígeno los cuales reaccionan con oxígeno molecular produciendo ozono (reacción 26), este puede seguir reaccionando con otros agentes para dar otros óxidos NOx (reacción 20 y 27), además puede catalizar la formación de especies sulfato en el mecanismo de sulfatación (reacción 9) dando en todas ellas oxígeno molecular como subproducto.

El ozono es un gas bastante reactivo y persistente, siendo el principal componente del smog fotoquímico causa efectos indeseables sobre la salud de los seres humanos puesto que provoca enfermedades de tipo respiratorio, además de ocasionar daños sobre construcciones de importancia cultural (Grøntoft, 2002). Aunque hasta ahora no se tiene gran cantidad de información acerca de sus efectos sobre los materiales, y menos en el caso particular de los que tienen importancia histórica, donde sus efectos son frecuentemente irreversibles, se conoce como se ha mostrado que tiene una relación de tipo 
sinérgico con otros contaminantes (Screpanti \& De Marco, 2009) evidenciadas en su facilidad para oxidar iones sulfito (puesto que es todavía más oxidante que el NO2) superficiales para formar sulfatos en condiciones tanto húmedas como secas (Massey, 1999), en otras palabras, el ozono tiene un efecto directo sobre la cinética de las reacciones dadas en los dos mecanismos de sulfatación expuestos acelerando la formación de indeseables costras de yeso.

\section{Corrosión de roca calcárea por acción del dióxido de carbono (CO2)}

Así como se han descrito los mecanismos de nitración y sulfatación, el dióxido de carbono $\mathrm{CO}_{2}$, al ser un componente mayoritario de la atmósfera interviene también en el proceso de corrosión química de las rocas calcáreas de monumentos de importancia cultural. El CO2 actúa mediante el siguiente mecanismo de corrosión:

$$
\begin{gathered}
\mathrm{CO}_{2}+\mathrm{H}_{2} \mathrm{O} \leftrightharpoons \mathrm{H}_{2} \mathrm{CO}_{3}(28) \\
\mathrm{CaCO}_{3}+\mathrm{H}_{2} \mathrm{O}+\mathrm{CO}_{2} \leftrightharpoons \mathrm{Ca}\left(\mathrm{HCO}_{3}\right)_{2}(29) \\
\text { Mecanismo } 6
\end{gathered}
$$

En este mecanismo conocido como carbonatación, hay primero una disolución en agua del dióxido de carbono, el cual se transforma en el ácido carbónico (reacción 28) que luego reacciona químicamente con el carbonato de calcio produciendo el respectivo bicarbonato (reacción 29), este bicarbonato de calcio es cien veces más soluble que el carbonato de calcio (Harris, 2001; Johnson et al., 1996), por lo que tal y como ocurre con el yeso hay pérdidas de material cuando el agua lluvia solubiliza el bicarbonato de calcio.

En síntesis, se puede decir que la degradación de rocas calcáreas por interacción con contaminantes atmosféricos se da a través de la lluvia cuya agua ha disuelto dióxido de carbono $p H \sim 5,6$, lluvias un poco más ácidas por disolución de ácidos como el nítrico y el sulfúrico, además de la deposición seca de contaminantes como el $\mathrm{SO}_{2}$ y los $\mathrm{NOx}$. Los procesos de deterioro que se acaban de explicar dependen directamente de la dirección de los vientos y del régimen de precipitaciones, de la microestructura del material pétreo además de su geometría intrínseca (Bonazza et al., 2009). La interacción de la roca conformante de las edificaciones de interés histórico con los contaminantes atmosféricos $\left(\mathrm{SO}_{2} / \mathrm{H}_{2} \mathrm{SO}_{4}, \mathrm{CO}_{2} / \mathrm{H}_{2} \mathrm{CO}_{3}\right.$, y $\mathrm{NOx}$, $\mathrm{HNO}_{3}, \mathrm{HNO}_{2}$ ) producidos en gran proporción por actividades antropogénicas como procesos de combustión provocan la formación de costras en forma de dendritas en las cuales las partículas carbonáceas dadas, las esporas, polen y polvo están también integradas, de todos estos, el daño que ocasiona el dióxido de azufre es el más agresivo (Massey, 1999; Marimoni et al., 2003; Watt et al., 2009) por formación de yeso, la cualidad de las sales que se acaban de describir de ser delicuescentes es lo que ocasiona daños irreversibles sobre los monumentos de interés histórico. 


\section{Corrosión de rocas calcáreas por acción de contaminantes de naturaleza orgánica}

Ampliamente se ha aceptado que el deterioro de piedra de monumentos de importancia cultural se debe a la interacción de esta con contaminantes atmosféricos (especialmente NOx y SOx) los cuales tienen una mayor presencia en zonas industrializadas, esta interacción se evidencia por la formación de una costra exterior de color negro (por formación de sales como yeso a través del mecanismo de sulfatación, además de la adhesión seca de partículas materiales) (Ghedini, Sabbioni \& Pantani, 2003; Grossi et al., 2003; McAlister, Smith, Török, 2008; Orecchio, 2010).

Sin embargo, los contaminantes de naturaleza orgánica contribuyen también al deterioro de estas estructuras, siendo los principales los PAHs (hidrocarburos poliaromáticos) que resultan de la actividad de quema de biomasa y combustibles fósiles como carbón y petróleo. Su presencia sobre las costras negras de las rocas es compleja debido a la presencia de compuestos alquil-sustituidos; los hidrocarburos poliaromáticos más comúnmente encontrados poseen de dos a seis anillos aromáticos. El material orgánico extraíble de costras negras consiste principalmente de hidrocarburos alifáticos en forma de n-alcanos $\left(\mathrm{C}_{8}\right.$ a $\left.\mathrm{C}_{32}\right)$ y ácidos grasos en forma de metil ésteres de cadenas largas $\left(\mathrm{C}_{4}\right.$ a $\left.\mathrm{C}_{30}\right)$, diterpenoides, esteranos y dialquil ftalatos cuando se habla de fuentes antropogénicas (SaizJiménez, 1997; Ghedini et al., 2000). El deterioro causado por contaminantes orgánicos tiene el siguiente mecanismo general, en el que un ácido carboxílico reacciona con el carbonato de calcio de la superficie de la roca calcárea para producir la sal cálcica soluble correspondiente junto con ácido carbónico (reacción de acción de protones). En el caso en el que el ácido sea polifuncional se tendrá entonces una reacción de quelación (Sand, 1997) como se muestra en el mecanismo 8 para el caso de un ácido dicarboxílico como el oxálico:
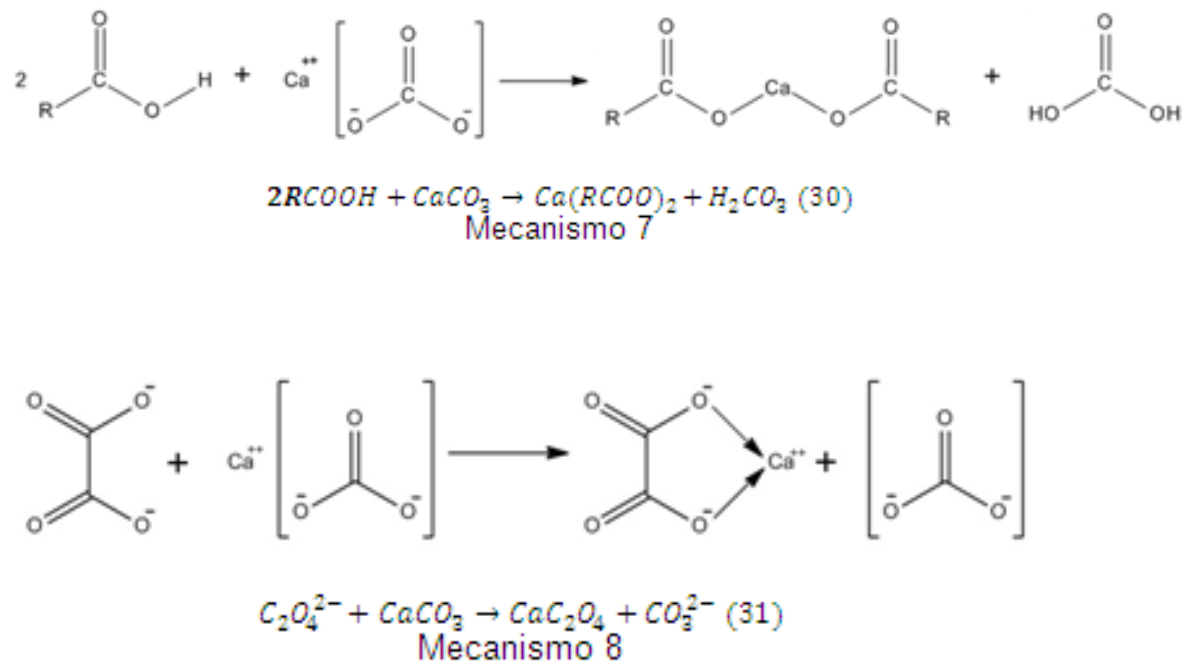
En otras palabras, los ácidos orgánicos tienen una fuente principalmente biológica, esto es, se producen por excreciones de microorganismos a través de sus metabolismos.

El ácido oxálico es un ácido dicarboxílico que puede coordinarse por dos sitios al calcio del carbonato de calcio del material pétreo desplazando al ión carbonato y formando la sal oxalato de calcio, un mecanismo similar siguen los ácidos polifuncionales como el cítrico, málico, succínico, y oxalacético.

Los ácidos monofuncionales como el glucónico, acético, glucurónico, y glioxílico también son excretados por los microorganismos y siguen un mecanismo distinto. El efecto de deterioro por ácidos orgánicos es comparable al de los ácidos inorgánicos. Los compuestos orgánicos que se han mencionado son los más representativos en cuanto a biodeterioro se refiere (Scheerer, Ortega-Morales \& Gaylarde, 2009).

\section{MECANISMOS DE ACCIÓN DE LOS ORGANISMOS CAUSANTES DE BIODETERIORO EN ROCA CALCÁREA DE MONUMENTOS HISTÓRICOS}

\section{Breve introducción al biodeterioro de rocas calcáreas}

Los monumentos históricos de importancia cultural pueden ser deteriorados tanto física como químicamente, dañándose estética y estructuralmente como ya se ha descrito. Sin embargo, existen agentes biológicos evidenciados a través del crecimiento y actividad de organismos vivos, los cuales causan un efecto no menos preocupante denominado biodeterioro.

El biodeterioro se define como el cambio indeseable en las propiedades de un material determinado por la presencia y acción metabólica de organismos vivos. A pesar de que las rocas calcáreas suelen ser biológicamente pobres en nutrientes, altamente susceptibles a cambios de humedad, a la erosión que causa el viento y a las altas dosis de radiación UV que reciben del sol, ensayos científicos han demostrado la presencia de un grupo particular de organismos biodeteriorantes que se agrupan en ecosistemas complejos conocidos como biofilms sobre y dentro de la superficie de estas. Estos organismos son principalmente hongos, bacterias, algas, protozoos y una variedad de pequeños animales y plantas (Gaylarde \& Gaylarde, 2005).

El biodeterioro ha sido ampliamente documentado como un proceso de degradación que en las rocas calcáreas se inicia una vez ha avanzado considerablemente el deterioro químico que causan los contaminantes atmosféricos de naturaleza inorgánica y orgánica descritos en secciones anteriores, puesto que estas sustancias son fuentes directas de nutrientes que permiten que los organismos biodeteriorantes proliferen. 
El desarrollo de las especies biológicas mencionadas anteriormente en la superficie de rocas calcáreas, está determinado por sus propiedades intrínsecas como son: constituyentes minerales, $\mathrm{pH}$, salinidad, porosidad, color, forma y textura, además de agentes medioambientales como contenido de humedad, condiciones de luz solar, concentración de contaminantes ambientales, partículas, temperatura, cercanía a costas, régimen de vientos y de lluvias. En otras palabras, la presencia de tales organismos potencialmente biodeteriorantes depende de los requerimientos ecológicos y fisiológicos que pudiera ofrecerle la roca calcárea, dichos requerimientos dan sentido a lo que se conoce como biorreceptividad, que se define como la capacidad que tiene la roca de ser colonizada por uno o varios grupos de organismos vivos o también como la totalidad de propiedades del material que contribuyen al establecimiento, desarrollo y anclaje de fauna o flora; el concepto que se deriva del término "susceptibilidad" usado en el campo de la medicina ampliamente implica una relación ecológica cercana entre la roca y el organismo colonizante. La biorreceptividad no puede ser definida como una propiedad estática y más de un tipo de biorreceptividad debe ser definido para cada tipo de material pétreo de acuerdo con las diferentes etapas de deterioro que haya sufrido, así, Guillite (1995) define tres tipos fundamentales de biorreceptividad: "la biorreceptividad primaria o intrínseca" la cual se refiere al potencial inicial que tienen las rocas de sufrir colonización biológica, "biorreceptividad secundaria" la cual se refiere a la susceptibilidad de las rocas meteorizadas de ser colonizadas, y "biorreceptividad terciaria" la cual es la medida de una potencial colonización a rocas sometidas a procesos de restauración. Se debe tener en cuenta sin embargo que en algunos casos un tipo específico de biorreceptividad de un material dado no depende totalmente de las propiedades intrínsecas del material, sino que esta propiedad puede verse afectada por la presencia en el sustrato calcáreo de sustancias depositadas del exterior como polvo y partículas que se depositan sobre el material pétreo y que pueden alterar su biorreceptividad. En tal caso se suele usar el término biorreceptividad extrínseca, la cual es aquella que depende directamente de las propiedades del material y de los depósitos exógenos que se adhieren sobre él (Guillite, 1995; Warscheid \& Braams, 2000; Salvadori \& Charola, 2009; Miller et al., 2012). De una manera general, todos los organismos vivos pueden ser clasificados como autótrofos o heterótrofos teniendo en cuenta su requerimiento nutricional. Para todos los organismos autótrofos, los constituyentes inorgánicos representarán sustancias potencialmente nutritivas lo que incrementará su velocidad de crecimiento. Por otro lado, los organismos heterótrofos prosperan solamente cuando hay presencia de materia orgánica en la superficie, así, para los organismos biodeteriorantes se tendrán entonces organismos fotoautótrofos o fotolitótrofos los cuales usan la luz solar como fuente de energía y al dióxido de carbono como su fuente principal de carbono; quimioautótrofos o quimiolitótrofos son aquellos que usan sustratos de naturaleza inorgánica como fuente de energía y dióxido de carbono como fuente principal de carbono; fotoheterótrofos o fotoorganótrofos usan luz solar como fuente 
de energía (son fotosintéticos) que no pueden convertir dióxido de carbono en carbono orgánico sino que más bien utilizan sustratos orgánicos; y quimioheterótrofos o quimioorganótrofos que usan compuestos de naturaleza orgánica como fuente de carbono y energía (Tomaselli et al., 2000; Gaylarde \& Crispim, 2005). La mayoría de los organismos sin importar su clasificación como autótrofos o heterótrofos, muestran una marcada tendencia a preferir superficies con altos contenidos de humedad.

Los organismos biodeteriorantes pueden ser superficiales o endolíticos, estos últimos a su vez se dividen en chasmoendolíticos y criptoendolíticos de acuerdo con el hecho de si establecidos dentro de la roca colonizan sus fisuras o sus poros, respectivamente.

Los organismos endolíticos son considerablemente perjudiciales y agresivos en comparación con los superficiales dado que al proliferar en el interior de las rocas son capaces de sobrevivir a condiciones extremas de temperatura, radiación UV y desecación dadas en el exterior (Gaylarde, Gaylarde \& Neilan, 2012).

\section{Principales organismos causantes de biodeterioro}

El proceso de biodeterioro de rocas calcáreas de importancia cultural e histórica es complejo e involucra a bacterias, cianobacterias, hongos como levaduras negras, hongos meristemáticos como primeros colonizantes y a algas, líquenes, musgos y plantas superiores como colonizantes secundarios. Estas comunidades de microorganismos varían en composición de acuerdo con las condiciones climáticas, naturaleza del sustrato, así como qué tanto ha estado expuesta al aire la superficie de la roca (Gómez-Bolea et al., 2011). A continuación se describirán los principales organismos causantes de biodeterioro de rocas calcáreas, explicando los mecanismos de los agentes químicos que excretan y las reacciones químicas de estas con el carbonato de calcio como principal componente químico de las rocas calcáreas.

\section{Algas}

Las algas son un grupo diverso de organismos fotoautotróficos eucarióticos unicelulares o multicelulares de diversas formas que contienen pigmentos como clorofila, carotenoides y xantofilas. Algunas algas son capaces de sobrevivir de forma heterotrófica cuando sea necesario. Dos especies de algas, las clorofitas y bacilariofitas han sido mayormente aisladas de monumentos de roca calcárea en regiones tropicales.

Las condiciones más importantes para el establecimiento de algas en este material son: humedad, calor, luz y sustratos de naturaleza inorgánica particularmente calcio y magnesio. Muchas algas muestran una sensibilidad aumentada al $\mathrm{pH}$ de la superficie prefiriendo las ácidas aunque este no siempre es un factor limitante de su crecimiento. 
Basados en su relación con el sustrato, las algas pueden ser divididas en dos grupos, algas epifíticas las cuales crecen en la superficie expuesta del sustrato. Y las algas endolíticas los cuales colonizan en cavidades o fisuras estructurales ya formadas.

El biodeterioro de rocas calcáreas relacionado con algas se evidencia en la pérdida de valor estético del monumento toda vez que las algas forman una pátina de variable extensión, grosor, consistencia y color. Tales pátinas suelen ser verdes, grises o negras. Sin embargo, en lugares poco expuestos a la intemperie tienen una tonalidad variable de colores como verde, amarillo, naranja, violeta y rojo. Las algas causan deterioro primeramente por manchado de la roca y la superficie de la misma. El manchado generalmente resulta de los diferentes pigmentos coloreados de las algas.

Aunque el daño producido por las algas puede no ser siempre severo, de forma indirecta crea las condiciones necesarias para el establecimiento de líquenes, plantas superiores, musgos, entre otros.

Las algas pueden también causar biodeterioro bioquímico. Producen, al igual que los hongos, metabolitos de naturaleza predominantemente orgánica. Tales ácidos disuelven activamente los constituyentes de la roca o incrementan su solubilidad en agua y estimulan la migración de sales en la matriz de la roca causando eflorescencias en su superficie. EI cambio en la solubilidad de los componentes de la roca calcárea altera propiedades de la roca como su coeficiente de expansión térmica, el cual puede incrementar la sensibilidad de la misma a procesos físicos de deterioro. Las algas secretan otras sustancias más complejas como proteínas las cuales actúan como agentes quelantes y contribuyen a la disolución de la roca, y azúcares que causan la aparición de bacterias heterotróficas epifíticas. Así, el crecimiento de algas produce, junto con el efecto de disolución del agua, la formación de microcavidades en la roca (Kumar \& Kumar, 1999).

\section{Bacterias}

Las bacterias son un grupo de organismos colonizantes unicelulares procarióticos de varias formas (esféricos, espirales y cilíndricos). Pueden ser móviles o inmóviles e incluyen especies tanto autotróficas como heterotróficas. Teniendo en cuenta que sus necesidades nutricionales y ecológicas son poco complejas, se desarrollan y prosperan sobre roca calcárea de importancia cultural y otros objetos expuestos a la intemperie especialmente cuando el contenido de humedad de los mismos es alto. La formación de costras negras, pátinas marrones, y exfoliación son las principales evidencias de la presencia de bacterias en monumentos calcáreos.

Hay cuatro principales tipos de bacterias que se han identificado son las principales causantes de biodeterioro en 
rocas calcáreas tales como oxidantes de sulfuro, nitrificantes, cianobacterias y actinomicetos.

\section{1) Actinomicetos}

Los actinomicetos son un grupo de bacterias en su mayoría aeróbicos, heterótrofos que en un principio fueron considerados hongos microscópicos dado que solían exhibir pequeños micelios o hifas ramificados durante la mayoría o todas las fases de su ciclo de vida. Suelen ocurrir ampliamente junto con hongos, algas y bacterias fijadoras de nitrógeno en ambientes caracterizados por la presencia de rangos de temperatura comprendidos entre 10 y $30^{\circ} \mathrm{C}$, humedad constante relativamente alta $(90-100 \%)$ y la presencia de materia orgánica (Kumar \& Kumar, 1999).

Los actinomicetos pertenecientes al género streptomyces son los más comunes y principales causantes de biodeterioro físico de rocas calcáreas a través de penetraciones similares a las que ocasionan los hongos; además, excretan una variada gama de enzimas y ciertos pigmentos oscuros capaces de hidrolizar y solubilizar la matriz superficial pétrea de los monumentos además de producir un velo de color blanquecino a modo de eflorescencia (Krumbein \& Gorbushina, 2009). Experimentos de laboratorio han demostrado su capacidad de usar nitritos y nitratos para reducir sulfatos, además se ha evidenciado su capacidad de secretar ácidos como oxálico y cítrico como productos directos de sus actividades metabólicas, los cuales solubilizan el material pétreo conformante de los monumentos históricos y además funcionan como agentes quelatantes de calcio.

La ocurrencia de actinomicetos se da en la mayoría de los casos junto con hongos, algas y bacterias nitrificantes, sin embargo más allá de su capacidad para liberar sustancias químicas ácidas corrosivas su acción biodeteriorante más evidente es la penetración de sus filamentos a través de la superficie producto de su tendencia a comportarse como colonizantes endolíticos (Scheerer, Ortega-Morales \& Gaylarde, 2009).

\section{2) Cianobacterias}

Las cianobacterias son organismos procarióticos, fotosintéticos, gram negativos inmóviles y altamente colonizantes que ocurren en formas tanto cocoides como filamentosas. De todos los microorganismos biodeteriorantes mencionados en este artículo, las cianobacterias ocupan casi la totalidad de la biomasa disponible (Crispim, Gaylarde \& Gaylarde, 2004). Son junto con las algas, los primeros colonizantes de rocas calcáreas (dada su naturaleza fotoautotrófica y su nula necesidad de materia orgánica para establecerse) y junto a los líquenes los organismos biodeteriorantes más resistentes (Scheerer, Ortega-Morales \& Gaylarde, 2009). Se caracterizan por hallarse recubiertas por una funda pigmentada que puede estar compuesta de clorofila, carotenoides, xantofilas, ficocianinas y ficoeritrinas que les imparten múltiples colores 
tales como dorado, amarillo, marrón, rojo, verde esmeralda, azul oscuro y violeta, causando biodeterioro estético del monumento. Además, dicho recubrimiento pigmentado les permite resistir condiciones extremas de exposición a la luz UV, y les confiere la capacidad de absorber humedad de manera rápida y liberarla de forma muy lenta, lo que les permite sobrevivir en ambientes extremadamente secos además de fijar nitrógeno (Crispim et al., 2006).

El biodeterioro de rocas calcáreas causado por cianobacterias se debe a su tendencia a formar biofilms endolíticos, que causan una sobrepresión en las fisuras preexistentes en las mismas como resultado de la absorción de humedad, la precipitación de oxalatos y carbonatos alrededor de sus células. El incremento en el tamaño de dichas fisuras permite el ingreso de polvo, polen, hongos, granos y pequeños animales como ácaros (Crispim \& Gaylarde, 2004).

Las cianobacterias epilíticas (superficiales) por su parte crean un microambiente donde el proceso de respiración y fotosíntesis produce sustancias ácidas como subproductos, los cuales causan solubilización del material calcáreo provocando posteriormente pérdidas de material y eflorescencias (GómezBolea et al., 2011).

\section{3) Bacterias nitrificantes}

Las bacterias quimiolitoautotróficas obtienen su alimento de la oxidación de sustancias inorgánicas reducidas. Usan dióxido de carbono como fuente principal de carbono.

Las bacterias nitrificantes se encuentran comúnmente en superficies deterioradas de material pétreo, las especies más comunes son: nitrosomonas, nitrosococos y nitrosospiras. El régimen de precipitaciones es responsable de la deposición sobre la superficie de monumentos de iones amonio y nitrito disueltos, los cuales provienen de fuentes tales como fertilizantes, estiércol de aves, vehículos, suelos, entre otras. Estas bacterias son, entonces, responsables de oxidar el amonio de acuerdo con el siguiente mecanismo en dos pasos denominado nitrificación (Mansch \& Bock, 1998):

$$
\mathrm{NH}_{4}^{+}+\frac{3}{2} \mathrm{O}_{2} \rightarrow 2 \mathrm{H}^{+}+\mathrm{NO}_{2}^{-}+\mathrm{H}_{2} \mathrm{O}
$$

El primer paso del proceso de nitrificación implica la oxidación de iones amonio por parte de bacterias nitrificantes quimioautotróficas como las nitrosomonas y los nitrosovibrios, luego, los nitritos producidos en la reacción (32) son oxidados a trióxido de nitrógeno así:

$$
\mathrm{NO}_{2}^{-}+\frac{1}{2} \mathrm{O}_{2} \rightarrow \mathrm{NO}_{3}
$$


En este segundo paso, la oxidación de nitritos se da por la intervención de bacterias oxidantes de nitritos tales como nitrobacters, nitrosococos y nitrosospiras.

El mecanismo general de la reacción de nitrificación es entonces:

$$
\mathrm{NH}_{4}^{+}+2 \mathrm{O}_{2} \underset{\text { Mecanismo } 7}{\longrightarrow} \mathrm{NO}_{3}+2 \mathrm{H}^{+}+\mathrm{H}_{2} \mathrm{O}(34)
$$

El trióxido de nitrógeno así formado sigue la secuencia de reacciones dada en el mecanismo 4 para producir ácido nítrico, que luego de reaccionar con carbonato de calcio produce finalmente nitrato de calcio el cual es más soluble que el carbonato de calcio, y por tanto puede ser fácilmente retirado de la superficie por acción de la lluvia causando pérdidas de material además de eflorescencias poco atractivas estéticamente (Warscheid \& Braams, 2000).

El principal efecto indeseable que causan las bacterias nitrificantes es el cambio en las propiedades de la roca la cual se hace más porosa, polvorienta, con tonalidades amarillas dada la formación de óxidos de hierro (Watt et al., 2009).

\section{4) Bacterias oxidantes de azufre}

Las bacterias oxidantes de azufre de las cuales las Thiobacillus $\mathrm{sp}$ son las más comunes representantes son organismos quimiolitotróficos, obtienen energía de la oxidación a ácido sulfúrico de azufre elemental o reducido principalmente $\mathrm{H}_{2} \mathrm{~S}$, $\mathrm{SO}^{\wedge}(2-/ 3)$, en presencia de especies nitrogenadas como $\mathrm{NH}_{3}, \mathrm{y}$ $\mathrm{NO}_{2^{-}}$(Warscheid \& Braams, 2000). El ácido sulfúrico puede reaccionar con el carbonato de calcio (reacción 16) para dar sulfato de calcio (yeso) el cual es más soluble en agua que el carbonato de la roca de origen, por lo que al igual que como ocurre con las bacterias nitrificantes se da un desprendimiento en la superficie de la misma, toda vez que esta sal se disuelve en agua proveniente del régimen de lluvias (Scheerer, OrtegaMorales \& Gaylarde, 2009). Además, el yeso formado en la superficie forma una costra negruzca que afea estéticamente la superficie de las rocas conformantes de los monumentos. Los sulfatos producidos por las bacterias oxidantes de azufre pueden ingresar a los poros de las rocas y recristalizarse, lo que produce sobrepresión en la matriz de la roca debilitándola irreversiblemente (Fernandes, 2006).

\section{Hongos}

Los hongos son un conjunto de organismos quimioheterótrofos que se caracterizan por poseer hifas filamentosas unicelulares 0 pluricelulares. Se distinguen de otros agentes biodeteriorantes como las bacterias por la ausencia en ellos de clorofila, y por lo tanto su incapacidad de producir su propio alimento a través de la luz solar. Suelen clasificarse en filamentosos como hifomicetos y coelomycetos además de microcoloniales como 
hongos meristemáticos similares a levaduras y levaduras negras. Los hongos meristemáticos son metabólicamente activos en condiciones extremas de desecación, radiación UV y estrés osmótico, lo que les confiere la capacidad de sobrevivir en rocas expuestas a la intemperie. Por su parte, los hongos filamentosos como los hifomicetos prefieren climas más fríos como los que se suelen dar en zonas nórdicas de Europa, aunque eso no les impide colonizar también rocas ubicadas en zonas subtropicales.

Aunque varias especies de hongos han sido aisladas de rocas meteorizadas, especialmente en zonas tropicales, el hecho de ser heterótrofos limita su capacidad de prosperar en rocas calcáreas, incluso si la humedad microclimática es alta, además, la naturaleza inorgánica del material pétreo que se describe en esta revisión en principio no favorece en nada el crecimiento de estos organismos, a menos de que exista una fuente de sustratos de naturaleza orgánica que permita su establecimiento, crecimiento y proliferación. Los desechos dejados por algas y bacterias (como las células muertas dejadas por estos organismos), hojas de plantas y heces de animales como aves, son fuentes principales de este tipo de sustratos (Kumar \& Kumar, 1999).

El biodeterioro fúngico puede ser mecánico y químico. En el primer caso se produce una penetración endolítica de sus hifas a través de la superficie de la roca debido a que no necesitan la luz solar para sobrevivir, debilitando la estructura de los monumentos por la aparición de grietas y fisuras.

El biodeterioro físico proporciona las condiciones para hacer al material pétreo más susceptible a otros factores de biodeterioro particularmente bioquímicos, los cuales se fundamentan en procesos de naturaleza asimilatoria (uso de matriz calcárea como fuente directa de nutrientes) así como procesos de naturaleza desasimilatoria, en donde los organismos, en este caso los hongos, excretan metabolitos y otras sustancias que reaccionan químicamente con la superficie del monumento. Se ha podido determinar de manera experimental que el daño que producen los hongos sobre rocas de interés cultural es principalmente químico, dado que son capaces de producir ácidos orgánicos tales como el glucónico (que es capaz de reaccionar con el carbonato de calcio conformante de roca calcárea como se muestra en el mecanismo 7), cítrico, oxálico y fumárico (que siguen reacciones de quelación de calcio a través del mecanismo 6). De los ácidos mencionados el glucónico es el más comúnmente excretado por hongos, además de otros que se liberan en menor medida tales como el ácido málico, succínico e itacónico (Gómez-Alarcón \& De la Torre, 1994).

Los hongos son capaces de producir pigmentos a base de melanina, lo cual produce decoloramiento de la superficie de la roca calcárea. La melanina hallada en las paredes celulares de los hongos los protege del ataque químico, por lo que difícilmente pueden ser eliminados a través de procesos antimicóticos (Mansch \& Bock, 1998; Sterflinger, 2010). 
Por otro lado, otro efecto no menos preocupante del biodeterioro causado por hongos tiene que ver con las sales orgánicas de calcio resultantes de la reacción entre el carbonato de calcio con ácido oxálico liberado por los mismos como son: la whewellita (oxalato de calcio monohidratado) y la wheddelita (oxalato de calcio dihidratado), las cuales producen eflorescencias en las superficies de los monumentos pétreos causando una costra poco atractiva estéticamente.

\section{Líquenes}

Los líquenes son un grupo de organismos compuestos por una relación simbiótica entre organismos como cianobacterias o algas (fotoautótrofos) y hongos (quimioheterótrofos). Juntos constituyen una estructura macroscópica simple llamada talo. Los talos liquénicos suelen crecer donde las algas y los hongos por sí solos no podrían sobrevivir, esta es la razón por la cual los líquenes son capaces de colonizar una gran variedad de sustratos tales como madera, suelos, materiales vítreos y en el caso que nos concierne a rocas. El pH de las rocas que son colonizadas por los líquenes determinan su naturaleza, así, en rocas de naturaleza calcárea se desarrollan especies afines al calcio dado que su pH es alcalino. Los líquenes pueden ser de diversas formas dependiendo de los organismos simbióticos que los conformen, los más comunes son los talos crustáceos, foliosos, fruticulosos y endolíticos (Hale, 1980; Allsopp, Seal \& Gaylarde, 2004). Los talos crustáceos son aquellos que se adhieren e inclusive penetran fuertemente a la roca calcárea formando una íntima asociación con esta por lo que son muy difíciles de erradicar, tanto, que se necesitaría remover la superficie externa de la roca para poder hacerlo de manera efectiva. Los talos foliosos son menos agresivos que los crustáceos, adhiriéndose a la roca a través de estructuras a modo de "anclas" conocidas como rizoides los cuales pueden penetrar en la roca hasta distancias de 0,5 mm, pueden en contraste con los líquenes crustáceos ser removidos de manera relativamente sencilla de la superficie pétrea de importancia cultural (De los Ríos et al., 2009). Por su parte los líquenes fruticulosos se adhieren a la roca a través de rizoides en forma de botón, esta última forma de talo liquénico es más fácil de remover en comparación con los talos descritos en el sentido de que no se requiere ser muy invasivo para retirarlo ya que su adhesión a las rocas calcáreas es prácticamente superficial. Por último, los talos liquénicos endolíticos ocurren de forma exclusiva en rocas de naturaleza calcárea, se caracterizan por hallarse inmersos completamente en estas colonizándolas lo que imposibilita casi totalmente su distinción debido también a que son de color blanco. Generalmente son evidenciados cuando se están reproduciendo ya que del talo emergen cuerpos a modo de frutos dejando atrás pequeños orificios.

Cabe resaltar que al ser una relación simbiótica, los hongos se establecerán toda vez que se efectúe primeramente la colonización de organismos fotolitoautótrofos como las ya mencionadas algas y cianobacterias, ya que ellas se agrupan primeramente en biofilms ricos en biomasa y sustratos de naturaleza tanto orgánica (puesto que estos son los nutrientes 
que favorecen la ocurrencia de hongos) como inorgánica. De este modo, los líquenes son uno de los primeros colonizantes que biodeterioran monumentos de roca calcárea, además, dada su gran resistencia a la desecación, a las temperaturas extremas y a su eficiencia en la acumulación de nutrientes ocurren en una diversa variedad de hábitats incluyendo aquellas que normalmente serían hostiles para otras formas de vida. Es por ello que usualmente se los considera como los organismos biodeteriorantes más agresivos (Kumar \& Kumar, 1999).

Los líquenes pueden ser epifíticos o endolíticos dependiendo de si se establecen sobre o dentro de la superficie de la roca calcárea, respectivamente. Así, la mayor degradación biofísica que los talos causan se da por la penetración en los poros, fisuras y grietas preexistentes de las rocas calcáreas más específicamente los crustáceos.

\section{Plantas superiores}

Las plantas superiores son organismos fotoautótrofos que obtienen energía de la luz solar y dióxido de carbono de la atmósfera como fuente directa de carbono. En contraste con los organismos fotoheterótrofos, las plantas superiores no necesitan para establecerse en la superficie de las rocas calcáreas de monumentos históricos materia orgánica presente en la superficie de la roca (Warscheid \& Braams, 2000). Son organismos que cuentan con tejidos especializados y órganos tales como raíces, tallo y hojas lo que las diferencia en complejidad de otros agentes biodeteriorantes ya mencionados.

Pueden clasificarse como pteridofitas o espermatofitas sobre la base de la presencia o ausencia de semillas. La espermatofitas pueden clasificarse a su vez en gimnospermas y angiospermas de acuerdo con la presencia o ausencia de flores sobre las cuales se asientan los órganos reproductores.

El crecimiento de plantas sobre la superficie de monumentos de importancia cultural depende del material del que se ha construido; su estado de conservación; la humedad y el clima, además las plantas superiores requieren para su establecimiento las condiciones óptimas que otorgan la presencia del complejo ecosistema que conforman las algas, bacterias, hongos, líquenes e inclusive los desechos de pequeños animales (Scheerer, Ortega-Morales \& Gaylarde, 2009). Las plantas generalmente se toman más de 10 años en colonizar una estructura (Lisci, Monte \& Pacini, 2003). En este proceso de colonización, hay siempre plantas primitivas que causan daños menores como las plantas anuales y las perennes y que suelen ser desplazadas por plantas cuya penetración en la matriz de las rocas calcáreas es más agresiva, como por ejemplo árboles y pequeños arbustos cuyas raíces producen daños, colapsos estructurales y daños irreversibles como se muestra en la Figura 5. 
El mecanismo de biodeterioro de rocas calcáreas por acción de las plantas, es complejo y consiste de alteraciones tanto biofísicas como químicas de las rocas calcáreas conformantes de monumentos históricos. Dichas alteraciones biofísicas implican la penetración de raíces, lo que genera sobrepresión en las rocas y debilitamiento de su estructura dado que se pierde la cohesión entre rocas. En general, las plantas superiores solamente prosperan en grietas, fisuras $y$ macroporos preexistentes en la superficie pétrea (Allsopp, Seal \& Gaylarde, 2004).

Por su parte, el biodeterioro químico de rocas calcáreas de importancia histórica implica la disolución de carbonato de calcio por la liberación de exudados de naturaleza ácida como aminoácidos, carbohidratos, ácido oxálico, tartárico, cítrico y carbónico cuyos mecanismos han sido explicados en secciones anteriores.

Las plantas superiores también ocasionan la alteración de las condiciones microclimáticas de las rocas, ocasionando por ejemplo una retención prolongada de humedad lo cual favorece el crecimiento de microorganismos. Además, en zonas de alta contaminación atmosférica el ataque por agentes de naturaleza ácida puede ser más dramático en superficies húmedas. Sin embargo, un cambio en las condiciones microclimáticas no necesariamente es dañino para el monumento y, en cambio, puede ser un factor protector de futuras alteraciones dañinas en las rocas. Por ejemplo, un recubrimiento de hojas de plantas sobre la superficie puede contribuir a la reducción de la evaporación de la humedad, lo que conlleva a la reducción de los impactos dañinos que producen los procesos de cristalización de sales (Mansch \& Bock, 1998).

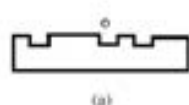

(a)

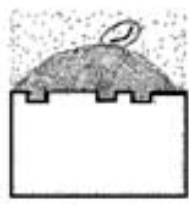

(6)

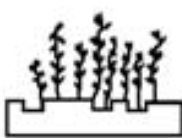

(b)

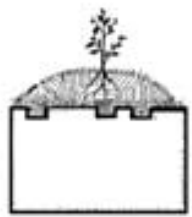

(1)

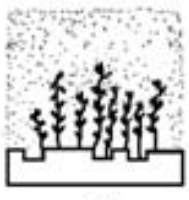

(6)

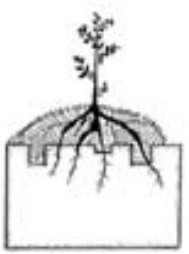

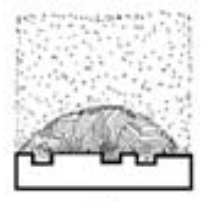

is

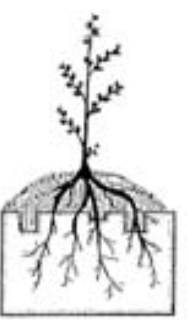

Figura 5. Sucesión de eventos en el biodeterioro de rocas calcáreas causadas por plantas superiores. (a) Primeramente una semilla de musgo se deposita sobre una grieta o fisura preexistente en la superficie rocosa, (b) con el paso del tiempo el viento va depositando alrededor del musgo una capa de polvo y partículas. (c) Se genera un sustrato denominado humus. (d) Se depositan semillas de plantas sobre el humus, (e) la planta germina, (f) crece, (g) florece, (h) el musgo no daña el humus en el que se asientan las plantas superiores sin embargo las raíces de las mismas penetran la matriz calcárea del monumento fracturándolo. 


\section{BIBLIOGRAFÍA}

- Al-Algha, M. R. (2006). Weathering of building stones and its relationship to the sustainable management of the aggregate resources in Gaza strip, Palestine. Building and environment, 41(5), 680, 681.

- Allsopp, D.; Seal, K. y Gaylarde, C. (2004). Introduction to biodeterioration. Cambridge University Press. 1, 3542, 143.

- Alves, C. A.; Sequeira Braga, M. A. y Trancoso, A. (2002). Saline pollution in trachyte monuments of the Azores islands (Portugal). Elsevier proceedings of the 9th international congress on deterioration and conservation of stone. 225.

- Andriani, G. F., Walsh, N. (2007). The effects of wetting and drying, and marine salt crystallization on calcarenite rocks used as building material in historic monuments. Geological society, London, special publications, 271, 179, 180.

- Bai, Y.; Thompson, G. E. y Martínez-Ramírez, S. (2006). Effects of NO2 on oxidation mechanisms of atmospheric pollutant so2 over Baumberger sandstone. Building and environment, 41, 490.

- Barbosa López, A.; Buendía, C. y Cortés, L. (2007). Estudio fisicoquímico del deterioro del material pétreo estructural antiguo de las murallas de Cartagena de Indias-Colombia (Baluarte de Santiago). Revista ciencias e ingenierías al día-Universidad de Cartagena, $1,101$.

- Bede, E. (2000). Characterization of surface morphology of carbonate stone and its effect on surface uptake of $\mathrm{SO}_{2}$. Elsevier proceedings of the 9th international congress on deterioration and conservation of stone. 303, 304.

- Bello, M. A. y Pérez Bernal, J. L. (2003). Modeling sulfur dioxide deposition on calcium carbonate. Ind. eng. chem. res, 42, 1028.

- Benavente, D.; García del Cura, M. A.; García-Guinea, J.; Sánchez-Moral, S. y Ordóñez, S. (2004). Role of pore structure in salt cristallization in unsaturated porous stone. Journal of crystal growth, 260, 532.

- Benavente, D.; Martínez-Martínez, J.; Cueto, N.; García del Cura, M. A. (2007). Salt weathering in dual-porosity building dolostones. Engineering geology, 94, 215, 216.

- Böke, H.; Göktürk, H. E.; Caner-Saltik, E. N. y Demirsi, Ş. (1999). Effect of airborne particle on SO2-calcite reaction. Applied surface science, 140, 70, 71, 74.

- Bonazza, A.; Messina, P.; Sabbioni, C.; Grossi, C. M. y Brimblecombe, P. (2009). Mapping the impact of climate change on surface recession of carbonate buildings in Europe. Science of the total environment, 407, 2039, 2040.

- Borgia, G. C.; Camaiti, M.; Cerri, F.; Fantazzini, P. y Piacenti, F. (2000). Study of water penetration in rock materials by NMR tomography: hydrophobic treatment effects. Journal of cultural heritage, 1, 128. 
- Camaiti, M.; Bugani, S.; Bernardi, E.; Morselli, L. y Matteini, M. (2007). Effect of atmospheric NOx on biocalcarenite coated with different conservation products. Applied geochemistry, 22, 1248.

- Camuffo, D. (1998). Microclimate for cultural heritage. Developments in atmospheric science 23 Elsevier science b.v. 12, 13.

- Cardell, C.; Benavente, D. y Rodríguez-Gordillo, J., (2008). Weathering of limestone building material by mixed sulfate solutions. Characterization of stone microstructure, reaction products and decay forms. Materials characterization, 59, 1371.

- Cardell, C.; Delalieux, F.; Roumpopoulos, K.; Moropoulou, A.; Auger, F. y Van Grieken, R. (2003). Salt-induced decay in calcareous stone monuments and buildings in a marine environment in sw France. Construction and building materials, 17, 165.

- Cataldo, R.; De Donno, A.; De Nunzio, G.; Leucci, G.; Nuzzo, L. y Siviero, S. (2005). Integrated methods for analysis of deterioration of cultural heritage: the Crypt of "Cattedrale di Otranto". Journal of cultural heritage, 6, 31.

- Charola, A. E. y Ware, R. (2002). Acid deposition and the deterioration of stone: A brief review of a broad topic. Geological society, London, special publications, 205, 393-399.

- Colston, B. J.; Watt, D. S. y Munro, H. L. (2001). Environmentally-induced stone decay: the cumulative effects of crystallization-hydration cycles on a Lincolnshire oopelsparite limestone. Journal of cultural heritage, 4, 304, 305.

- Coussy, O. (2006). Deformation and stress from in-pore drying-induced crystallization of salt. Journal of mechanics and physics of solids, 54, 1518, 1526.

- Crispim, A. C.; Gaylarde, M. P.; Gaylarde, C. C. y Brett, A. N. (2006). Deteriogenic cyanobacteria on historic buildings in Brazil detected by culture and molecular techniques. International biodeterioration and biodegradation, 57, 239, 240.

- Crispim, C. A. y Gaylarde, C. C. (2004). Cyanobacteria and biodeterioration of cultural heritage: a review. Microbial ecology, 49, 3.

- Crispim, C. A.; Gaylarde, C. C. y Gaylarde, P. M. (2004). Biofilms on church walls in Porto Alegre, rs, Brazil, with special attention to cyanobacteria. International biodeterioration and biodegradation, 54, 122.

- De los Ríos, A.; Cámara, B.; García del Cura, M.; Rico, V.; Galván, V. y Ascaso, C. (2009). Deteriorating effects of lichen and microbial colonization of carbonate building rocks in the Romanesque churches of Segovia (Spain). Science of the total environment, 407, 1127.

- Doehne, E. (2002). Salt weathering: a selective review. Geological society, London, special publications, 205, 51-56. 
- Doehne, E. y Price, C. (2010). Stone conservation, an overview of current research. The getty trust publications, 2, 15.

- Espinosa, R. M.; Franke, L. y Deckelmann, G. (2008). Predicting efflorescence and subflorescences of salts. Matter. res. soc. symp. proc., 1047.

- Espinosa-Marzal, R. y Scherer, G. W. (2010). Advances in understanding damage by salt crystallization. Accounts of chemical research, 43, 897-900.

- Fernandes, P. (2006). Applied microbiology and biotechnology in the conservation of stone cultural heritage materials. Applied microbiology and biotechnology, 73, 292.

- Flatt, R. J. (2002). Salt damage in porous materials: how high supersaturations are generated. Journal of crystal growth, 242, 435, 437.

- Flores, M.; Lorenzo, J. y Gómez-Alarcón, G., (1997). Algae and bacteria on historic monuments at Alcalá de Henares, Spain. International biodeterioration and biodegradation, 40, 244.

- Gaylarde, C. y Crispim, C. (2005). Cyanobacteria and biodeterioration of cultural heritage: a review. Microbial ecology, 49, 1.

- Gaylarde, C. y Gaylarde, P. (2005). A comparative study of the major microbial biomass of biofilms on exteriors of buildings in Europe and Latin America. International biodeterioration and biodegradation, 55, 131-133.

- Gaylarde, C.; Gaylarde, P. y Neilan, B. A. (2012). Endolithic phototrophs in built and natural stone. Current microbiology, 65, 183-8.

- Ghedini, N.; Gobbi, G.; Sabbioni, C. y Zappia, G. (2000). Determination of elemental and organic carbon on damaged stone monuments. Atmospheric environment, 34, 4383.

- Ghedini, N.; Sabbioni, C. y Pantani, M. (2003). Thermal analysis in cultural heritage safeguard: an application. Thermochimica acta, 406, 105.

- Giavarini, C.; Santarelli, M. L.; Natalini, R. y Freddi, F. (2008). A non-linear model of sulphation of porous stones: numerical simulations and preliminary laboratory assessments. Journal of cultural heritage, 9, 14, 15.

- Gómez-Alarcón, G. y De la Torre, M. A. (1994). The effect of filamentous fungi on stone monuments: the spanish experience. Building mycology, 13, 272.

- Gómez-Bolea, A.; Llop, E.; Ariño, X.; Sáiz-Jiménez, C.; Bonazza, A.; Messina, P. y Sabbioni, C. (2011). Mapping the impact of climate change on biomass accumulation on stone. Journal of cultural heritage, article in press, 2.

- Grøntoft, T. (2002). Dry deposition of ozone on building materials. Chamber measurements and modeling of the time-dependent deposition. Atmospheric environment, $36,5661$. 
- Grossi, C. M.; Esbert, R. M.; Díaz-Pache, F. y Alonso, F. J. (2003). Soiling of building stones in urban environments. Building and environment, 38, 147.

- Grossi, C. M. y Murray, M. (1999). Characteristic of carbonate building stones that influence the dry deposition of acidic gases. Construction and building materials, 13, 101, 103.

- Guillite, O. (1995). Bioreceptivity: a new concept for building ecology studies. Science of the total environment, 167, 215-220.

- Hale Jr., M E. (1980). Control of biological growths on Mayan archaeological ruins in Guatemala and Honduras. National geographic research reports, Washington D.C. 305-321.

- Harris, B. (2001). The weathering of limestone and the effect of airborne pollution. A discussion paper for the air quality working group of the bradford-on-avon preservation trust, 3, 4, 15.

- Herrera, L. K. y Videla, H. A. (2004). The importance of atmospheric effects on biodeterioration of cultural heritage constructional materials. International biodeterioration and biodegradation, 54, 125.

- Jain, K. y Mishra, A. K. (1993). Effect of atmospheric pollution on monuments and historic buildings. Environment manager division steel authority of India, 95, 96.

- Johnson, J. B.; Montgomery, M.; Thompson, G. E.; Wood, G. C.; Sage, P. W. y Cooke, M. J. (1996). The influence of combustion-derived pollutants on limestone deterioration: 1. the dry deposition of pollutant gases. Corrosion science, 38, 118.

- Kirkitsos, P. y Sikiotis, D. (1996). Deterioration of Pentelic marble, Portland limestone and Baumberger sandstone in laboratory exposures to $\mathrm{NO}_{2}$ : a comparison with exposures to $\mathrm{HNO}_{3}$. Atmospheric environment, 30, 941.

- Krumbein, W. y Gorbushina, A. (2009). The effects of air pollution on cultural heritage. Springer, 140.

- Kumar, R. y Kumar, A. (1999). Biodeterioration of stone in tropical environments: an overview. The getty conservation institute, research in conservation, 15, 16, 18-20, 25, 27.

- Lisci, M.; Monte, M. y Pacini, E. (2003). Lichens and higher plants on stone: a review. International biodeterioration and biodegradation, 51, 7-10.

- Liu Zhi, R.; Zhang Jian, B.; Zhang, H. y Shi Feng, M. (2011). Deterioration of Yungang grottoes: diagnosis and research. Journal of cultural heritage, article in press, 3.

- Lubelli, B.; Van Hees, R. P. y Groot, C. J. (2004). The role of sea salts in the occurrence of different damage mechanisms and decay patterns on brick masonry. Construction and building materials, 18, 121-124.

- Mansch, R. y Bock, E. (1998). Biodeterioration of natural stone with special reference to nitrifying bacteria. Biodegradation, 9, 49. 
- Marimoni, N.; Birelli, M. P.; Rostagno, C. y Pavese, A. (2003). The effects of atmospheric multipollutants on modern concrete. Atmospheric environment, 37, 4701, 4711.

- Massey, S. W. (1999). The effects of ozone and nox on the deterioration of calcareous stone. The science of the total environment, 227, 109, 112, 113.

- Maurício, A.; Pacheco, A.; Brito, P.; Castro, B.; Figuereido, C. y Aires-Barros, I. (2005). An ionic conductivity-based methodology for monitoring salt systems in monuments stones. Journal of cultural heritage, 6, 287, 288.

- McAlister, J. J.; Smith, B. J. y Török, A. (2008). Transition metals and water-soluble ions in deposits on a buildings and their potential catalysis of stone decay. Atmospheric environment, 42, 7657.

- Miller, A. Z.; Sanmartín, P.; Pereira-Pardo, L.; Dionísio, A.; Sáiz-Jiménez, C.; Macedo, M. F. y Prieto, B. (2012). Bioreceptivity of building stones: a review. Science of the total environment, 426, 5.

- Minotas Ruiz, J. (2002). Corrosión atmosférica importancia, principios generales, factores influyentes. Prevención y protección del patrimonio cultural iberoamericano de los efectos del biodeterioro ambiental. Memorias. 31, 32.

- Mitchell, R. y Gu, J. (2010). Environmental microbiology. Wiley-Blackwell, 2, 144-146.

- Mottershead, D.; Gorbushina, A.; Lucas, G. y Wright, J. (2003). The influence of marine salts, aspect and microbes in the weathering of sandstone in two historic structures. Building and environment, 38, 1193.

- Naresh, R.; Sundar, S. y Shukla, J. B. (2006). Modeling the removal of primary and secondary pollutants from the atmosphere of a city by rain. Applied mathematics and computation, 179, 282, 283.

- Nuhoglu, Y.; Oguz, E.; Uslu, H.; Ozbek, A.; Ipekoglu, I.; Ocak, I. y Hasenekoglu, I. (2006). The accelerating effect of the microorganisms on biodeterioration of stone monuments under air pollution and continentalcold climatic conditions in Erzurum, Turkey. Science of the total environment, 364, 273-274.

- Orecchio, S. (2010). Analytical method, pattern and sources of polycyclic aromatic hydrocarbons (pahs) in the stone of the temples of Agrigento (Italy). Journal of hazardous materials, 176, 339.

- Papida, S.; Murphy, W. y May, E. (2000). Enhancement of physical weathering of building stones by microbial populations. International biodeterioration and degradation, 46, 305, 306.

- Pérez Bernal, J. y Bello López, M. (2000). The fractal dimension of stone pore surface as weathering descriptor. Aplied surface science, 161, 47.

- Pesava, P.; Aksu, R.; Toprak, S.; Horvath, H. y Seidl, S. (1999). Dry deposition of particles to building surfaces and soiling. The science of the total environment, 235, 25-27. 
- Pope, G. A.; Meierding, T. C. y Paradise, T. R. (2002). Geomorphology's role in the study of weathering of cultural stone. Geomorphology, 47, 212.

- Rijniers, L. A.; Huinink, H. P.; Pel, L. y Kopinga, K. (2003). Salt crystallization as damage mechanism in porous building materials. Euromat 2003, Symposium p2 materials and conservation of cultural heritage, salt damage session.

- Ruedrich, J.; Seidel, M.; Rothert, E. y Siegesmund, S. (2007). Length changes of sandstones caused by salt cristallyzation. Geological society, London, Special publications, 271, 200.

- Ruiz-Agudo, E.; Mees, F.; Jacobs, P. y RodríguezNavarro, C. (2007). The role of saline solution properties on porous limestone salt weathering by magnesium and sodium sulfates. Environmental geology, 52, 269-281.

- Saiz-Jiménez, C. (1991). Characterization of organic compounds in weathered stones. Proceedings of European symposium in science, technology and European cultural heritage, 523-526.

- (1997). Biodeterioration vs biodegradation: the role of microorganisms in the removal of pollutants deposited on historic buildings. International biodeterioration and biodegradation, 40, 226, 227.

- Salvadori, O. y Charola, E. (2009). Methods to prevent biocolonization and recolonization: an overview of current research for architectural and archaeological heritage. Biocolonization of stone: control and preventive methods proceedings from the mci workshop series. Smithsonian contributions to museum conservation number 2, 38, 39.

- Sánchez Sanjurjo, J.; Vidal Romaní, J. R. y Alves, C. (2011). Deposition of particles on gypsum-rich coatings of historic buildings urban and rural environments. Construction and building materials, 25, 813.

- Sand, W. (1997). Microbial mechanisms of deterioration of inorganic substrates- A general mechanistic overview. International biodeterioration and biodegradation, 40, 186.

- Scheerer, S.; Ortega-Morales, O. y Gaylarde, C. (2009). Microbial deterioration of stone monuments- An updated overview. Advances in applied microbiology, 66, 99, 111, 112, 117, 123, 125.

- Screpanti, A. y De Marco, A. (2009). Corrosion on cultural heritage buildings in Italy: A role for ozone? Environmental pollution, 157, 1513.

- Sebastián, E.; Cultrone, G.; Benavente, D.; Fernández Linares, L.; Elert, K. y Rodríguez-Navarro, C. (2008). Swelling damage in clay-rich sandstones used in the church of San Mateo in Tarifa (Spain). Journal of cultural heritage, 9, 73.

- Silva, Z. S. y Simão, J. A. (2009). The role of salt fog on alteration of dimension stone. Construction and building materials, 23, 3326. 
- Slezakova, K.; Castro, D.; Begonha, A.; Delerue-Matos, C.; Alvim-Ferraz, M.; Morais, S. y Pereira, M. (2011). Air pollution from traffic emissions in Oporto, Portugal: health and environmental implications. Microchemical journal, 99, 51, 52.

- Sterflinger, K. (2010). Fungi: their role in deterioration of cultural heritage: review. Fungal biology reviews, 24, 49-51.

- Striegel, M. F.; Bede Guin, E.; Hallett, K.; Sandoval, D.; Swingle, R.; Knox, K.; Best, F. y Fornea, S. (2003). Air pollution, coatings, and cultural resources. Progress in organic coatings, 48, 282.

- Tittarelli, F.; Moriconi, G. y Bonazza, A. (2008). Atmospheric deterioration of cement plaster in a building exposed to a urban environment. Journal of cultural heritage, 9, 204.

- Tomaselli, L.; Lamenti, G.; Bosco, M. y Tiano, P. (2000). Biodiversity of photosynthetic micro-organisms dwelling on stone monuments. International biodeterioration and biodegradation, 46, 251.

- Ventikou, M.; Halls, C.; Lindsay, W.; Batchelder, M. y Hubbard, C. (2002). An evaluation of geology and weathering in the preservation of marl objects. Elsevier proceedings of the 9th international congress on deterioration and conservation of stone. 287.

- Warscheid, Th. y Braams, J. (2000). Biodeterioration of stone: a review. Journal of biodeterioration and biodegradation, 46, 343, 344, 347, 350, 352.

- Watt, J.; Tidblad, J.; Kucera, V. y Hamilton, R. (2009). The effects of air pollution on cultural heritage. Springer, 6, 10, 12, 14-16, 22-23, 138.

- Young, P. (1996). Pollution-fueled "biodeterioration" threatens historic stone. Environmental science and technology, 30, 206.

- Zanardini, E.; Abbruscato, P.; Ghedini, N.; Readini, M. y Sorlini, C. (2000). Influence of atmospheric pollutants on the biodeterioration of stone. International biodeterioration and biodegradation, 45, 35, 42.

- Zedef, V.; Kocak, K.; Doyen, A.; Ozsen, H. y Kekec, B. (2007). Effect of salt crystallization on stones of historical buildings and monuments, Konya, Central Turkey. Building and environment, 42, 1456.

1. Laboratorio de Investigaciones en Catálisis y nuevos Materiales LICATUC, Facultad de Ciencias Exactas y Naturales, Universidad de Cartagena, Campus de Zaragocilla, Cartagena, Colombia. Davidtatis19@gmail.com, celular: 320-5115651.

2. Laboratorio de Investigaciones en Catálisis y nuevos Materiales LICATUC, Facultad de Ciencias Exactas y Naturales, Universidad de Cartagena, Campus de Zaragocilla, Cartagena, Colombia. 